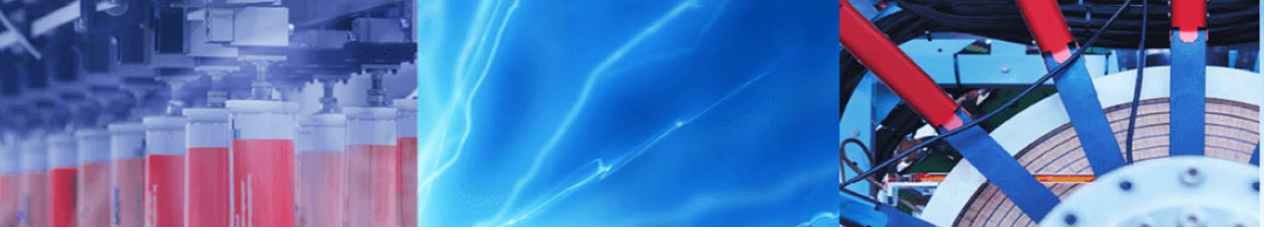

Research Article

\title{
Optimization of pulp and acid leaching operations in zinc ingot production process with the data mining approach
}

\author{
Shahrooz Bamdad ${ }^{1}$ (D)
}

Received: 14 September 2020 / Accepted: 9 March 2021 / Published online: 1 April 2021

(C) The Author(s) 2021 OPEN

\begin{abstract}
This study presents a data mining approach to optimize the chemical processes. Typically, these processes are affected by a variety of interactive variables. So, their quality monitoring and detection usually emphasize changing main variables and their interaction effects. Sometimes, the input to the chemical processes lacks access to the raw materials, which causes the manufacturers to use residue instead of high-quality materials. The use of residue has flaws, most notably the low quality of the process output. In this paper, calculating the optimum points of process variables using residue with the data mining approach is suggested. As a real case, one of the operations of the zinc ingot production process, i.e., pulp and acid leaching operations, are studied. In this way, first, by studying the operation in detail, the required data are collected, and key input and output variables are distinguished. Then, by data pre-processing, the optimum points of the process are determined using data mining algorithms. Therefore, the input variable settings of the operation are extracted to optimize the output variables. To validate the results, a set of test data are used to examine the two periods before and after the variable settings. The results show that the operation output is improved significantly. According to the robustness of the proposed method, it can be used as a benchmark for other chemical processes.
\end{abstract}

Keywords Chemical process $\cdot$ Mathematically modeling $\cdot$ Data mining

\section{Introduction}

Zinc is the fourth most widely used metal globally after iron, aluminum, and copper [1]. Zinc metal is used for the electrical plating of steel [2]. This metal, like other metals, reacts slowly. Applications of this metal include the die casting process in the automotive industry [3], as an activator in the rubber industry [4], skin protection [5], medical applications [6], cosmetics [7], and several other applications [8].

Zinc metal is produced from zinc mineral concentration [9]. This concentration usually contains elements such as lead, nickel, cobalt, cadmium, iron, and some other elements that are purified in the production process [10]. To produce zinc metal, mineral concentration is first crushed and ground. If there is lead in the concentration, it is removed by flotation. Afterward, being transferred to the furnace, these sulfur concentrations become oxidized and usable. After concentration preparation, leaching (liquid-solid extraction) is performed by sulfuric acid and water. In this way, the zinc in the concentration is dissolved by leaching and sulfate is obtained. In this way, other elements such as nickel, cobalt, cadmium, iron, and some other elements present in the concentration along with the zinc are dissolved. Therefore, these annoying ions must be removed before the electrolysis operation [11]. Potassium permanganate and hydrated lime are used to remove annoying ions [12].

One of the most important challenges for zinc ingot plants is access to zinc ore or concentrate. As a result, these

Shahrooz Bamdad, sh_bamdad@azad.ac.ir|'Department of Industrial Engineering, Islamic Azad University, South Tehran branch, Tehran, Iran. 
plants sometimes use residue due to the lack of access to high-grade concentration. The use of residue in the production process creates problems because the process is based on the input of mineral concentration. With the change of input, the parameters of the process also face many issues. The purpose of this paper is to optimize the parameters of pulp and acid leaching operations in the zinc production process using residue. The data mining approach is used to achieve this goal. Thus, first, the key input and output parameters of pulp and acid leach operation are extracted. Then, by collecting the required data, pre-processing is performed. In this stage, first, a secondorder polynomial regression model with interaction effects is fitted, and then the data are cleaned by identifying the outliers. The next step is to select the feature based on the stepwise regression and backward elimination algorithms. Thus, important and influential variables on pulp and acid leaching operations have been extracted. Finally, to optimize the operation's output, the settings of the process input variables are obtained.

The rest of this paper is presented as follows: First, the literature review is examined the background of related research, and then in the materials and methods section, the process, data, and methods are described. In the following, the findings are reported and analyzed. Finally, a conclusion has been drawn.

\section{Literature review}

The modeling of chemical processes like textile industry [13], dielectric technical ceramics [14], and spark plasma sintering densification [15] has been widely considered by researchers. Surface coating is modeled in a hot-dipped galvanized process. The scanning electron microscope, energy dispersive spectroscopy, and $\mathrm{x}$-ray diffraction factors are examined in this process. In this modeling, interactions between thermal condition and crystallization orientation are analyzed. Therefore, spangle morphology is classified into flat, feather, and coarse [16].

Modeling of metal alloys, including rolled AIZn alloys, has also been performed [17]. The AIZn liquid melt process is widely studied. In Table 1, the related papers are summarized.

Data analysis tools, especially data mining, have been widely used over the past decade. Applications of data mining include industrial applications, services, and other sections [28]. In general grouping, data mining methods are divided into descriptive and predictive categories. In descriptive methods such as clustering and frequent pattern discovery, significant data trends are discovered and modeled. These methods help comprehend the important parameters of the process and their interactions, and the researcher can use these methods to gain a deeper understanding of the process. Among the clustering methods, $k$-means, $k$-medoids, and fuzzy $c$-means can be mentioned [29]. In predictive methods such as classification, by examining the current or training data and determining the relationship between parameters, the future behavior of the process is predicted. In these methods, their future behavior can be predicted by extracting process characteristics.

Among the data mining methods, regression can be mentioned [30]. Amongst regression practices, stepwise methods are used to increase the accuracy of the models. Stepwise methods include backward elimination, forward selection, and stepwise regression. This method has been used to investigate heating and cooling load in buildings by selecting the best variables and cross production [31].

Machine learning and data mining applications in mineral processing can be categorized as (i) the nature

Table 1 Papers related to modeling chemical processes

\begin{tabular}{|c|c|c|}
\hline Process & Subject matter & Reference \\
\hline Al-Zn liquid melt & $\begin{array}{l}\text { Investigation of solidification such as stir casting, compo casting, pressurized solidification, squeeze } \\
\text { casting, and extrusion in the semisolid state }\end{array}$ & {$[18]$} \\
\hline Al-Zn liquid melt & Microstructural refinement & [18] \\
\hline Al-Zn liquid melt & Investigation of processing techniques that can help to reduce the degree of dimensional instability & [19] \\
\hline Al-Zn alloy & Investigation of mechanical properties & {$[20]$} \\
\hline Mg-Zn alloy & Hardening characteristics & {$[21]$} \\
\hline Mg-Zn alloy & Investigating the interaction between carbon nanotubes and aluminum & {$[22]$} \\
\hline $\begin{array}{l}\text { Alloy systems containing } \\
\text { nanoparticles }\end{array}$ & Modeling and simulation of deformation mechanisms & {$[23]$} \\
\hline Mg-Zn magnesium alloy & Evaluation of strength and ductility & {$[24]$} \\
\hline Mg-Zn-Y alloy & Evaluation of formation mechanism & {$[25]$} \\
\hline Mg-Zn-Y alloy & Discussion of strength & {$[26]$} \\
\hline Mg-Zn-Y alloy & Mechanical and strength properties investigation & {$[27]$} \\
\hline
\end{tabular}


of data, including synthetic, laboratory, and industrial, (ii) application area, i.e., leaching, floating, etc., (iii) methodology category, e.g., data-based modeling, fault diagnosis, and machine vision. Specifically, Strydom et al. used fault diagnosis methods to detect abnormal process conditions of atmospheric and pressure leach at the base metal refinery [32]. Data-based modeling, fault detection, and diagnosis methods were considered as well. For instance, simulations of mineral leaching processing systems are developed by Dorfling et al. [33, 34]. Meanwhile, dynamic modeling was used by Miskin et al. in a simulation of the high-pressure leaching process for fault detection from Western platinum Ltd. base metal refinery data [35]. They used principal component analysis to determine fault detection. Saldana et al. developed a discrete event simulation-based method to optimize the mineral recovery of the heap leaching phase considering the type of ore in the feed [36]. Li et al. introduced a data mining-based method in the Vanadium extraction industry using a weak acid leaching process [37]. They used support vector machines with a genetic algorithm to improve decision-making for cleaner production.

\section{Materials and methods}

\subsection{The process and data}

In this paper, zinc ingot production in one of the plants in Iran is analyzed. This factory supplies the required mineral concentration from the western mines of Iran and part of it as imports. The composition of the raw materials is: lowgrade $(8 \%-12 \%)$, high-grade $(18 \%-22 \%)$, special fill quality $(22 \%-28 \%)$, and recycled $(34 \%-38 \%)$. Due to the lack of access to high-grade concentration, the plant has also resorted to residue use.

The process of zinc ingots producing in this plant includes six operations:

(1) Pulping and acid leaching operations Since the concentration entering the process has a certain amount of zinc and a certain amount of impurities, first, the amount of zinc and concentration impurities are determined. The zinc concentration is then charged to the production line. The primary tank of the charging line is the pulp, which is used for grout making. Here, water and sulfuric acid are added to the tanks to activate zinc and impurities. Then in the acidic leach, the $\mathrm{H}_{2} \mathrm{SO}_{4}$ is added to the tank, and the $\mathrm{pH}$ value is in the range of 1.2-1.8. As a result, zinc and impurities are released into the solution.
(2) Neutral leaching operation In this operation, lime water is added to the solution to neutralize it. As a result, the $\mathrm{pH}$ value is in the range of 4.5-5.2. In this operation, the amount of $\mathrm{Fe}$ in the solution decreases from $600 \mathrm{ppm}$ to less than $20 \mathrm{ppm}$.

(3) Hot purification operation: In this stage, $\mathrm{KMnO}_{4}$ is added to the process solution. The goal of this step is to reduce the amount of cobalt, which is known as impurity, to less than $1.4 \mathrm{ppm}$. The output of this step is a solution with a $\mathrm{Zn}$ value of 75 to $85 \mathrm{~g}$ per liter and a Cobalt value of 1.2-1.4 ppm.

(4) Cold purification operation: The output of the previous step is poured into the tank, and then zinc powder is added to the tank to remove nickel and cadmium impurities. The output of this tank is called fresh or make-up. The fresh is free of impurities and rich in zinc ions.

(5) Electrolysis operation: The fresh solution enters the electrolysis part. In this section, there are anode and cathode plates that $\mathrm{Zn}$ sit on the cathode as a sheet by establishing electricity.

(6) Melting and casting operations: The sheets obtained from the electrolysis stage are transferred to the melting and casting rotary kiln, and after setting the temperature, they are melted into the casting molds, which are finally produced on the ingots.

Figure 1 shows a schematic of the zinc ingot production process.

The plant produces zinc ingots with grade $\mathrm{Zn}-3$, which according to ISO752 standard, its chemical composition is as Table 2.

Because in this process, the residue is used as input feed, the produced ingots are downgraded and its price in the market is drastically reduced. This paper examines pulping and acid leaching operations, which are the first steps in the process. In the case of residue usage, if the $\mathrm{Zn}$ concentration of the operation output is high, then the $\mathrm{Zn}-3$ grade can be achieved.

By carefully examining the pulp-making stage, the inputs and outputs of this stage were identified as Fig. 2.

Table 3 shows the input and output variables of pulp making.

The acid leaching stage also has inputs and outputs, as Fig. 3.

Table 4 shows the input and output variables of acid leaching.

By studying the pulping and acid leaching operations and also based on the opinions of the plant experts, it was determined that the output variable of this operation is the $\mathrm{Zn}$ concentration of acid grout ( $\mathrm{Zn}$ output of acid leaching). So, the output variable is a function of inputs as: 


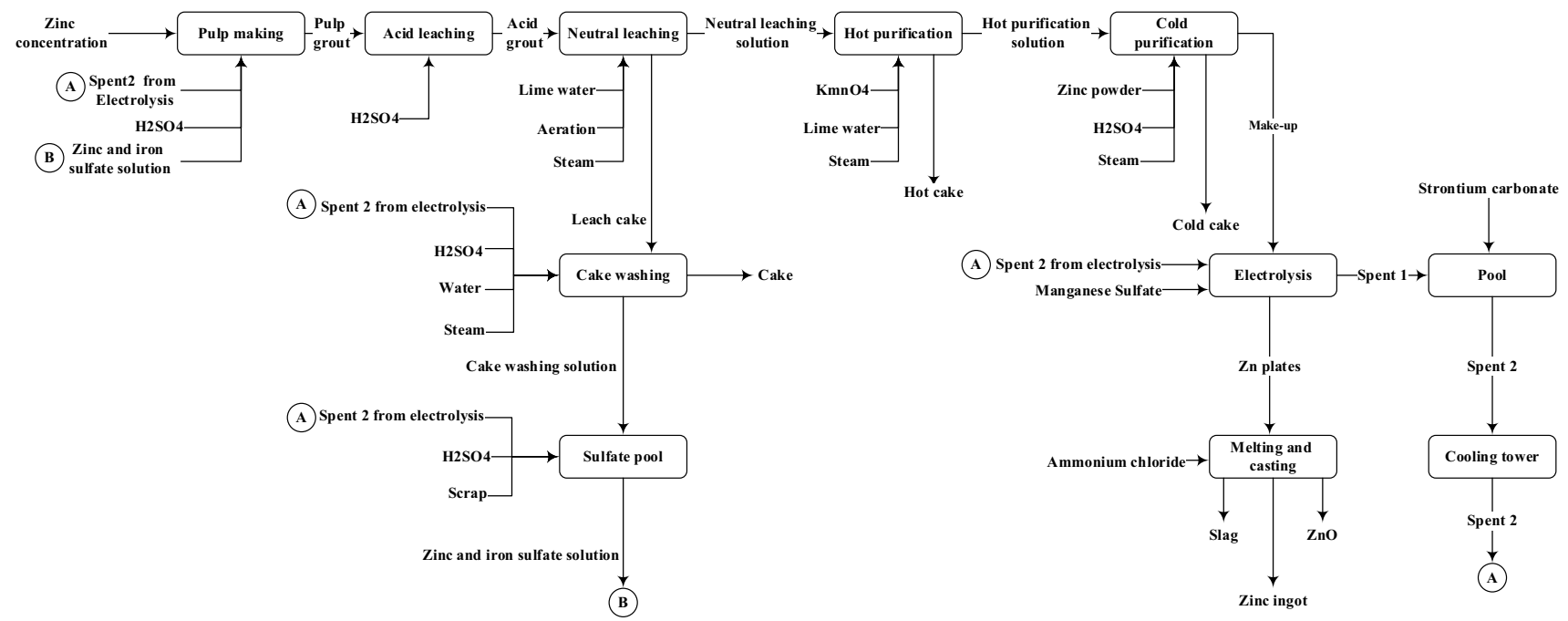

Fig. 1 Zinc ingot process schematic

Table 2 Chemical composition of zinc ingots with grade $\mathrm{Zn}-3$

\begin{tabular}{llllllllll}
\hline Designation & $\mathrm{Pb}$ & $\mathrm{Fe}$ & $\mathrm{Cd}$ & $\mathrm{Al}$ & $\mathrm{Cu}$ & $\mathrm{Sn}$ & Permitted total & Minimum Zinc content & Colour grade \\
\hline $\mathrm{Zn}-3$ & 0.03 & 0.02 & 0.01 & 0.1 & 0.002 & 0.001 & 0.05 & 99.95 & Green \\
\hline
\end{tabular}

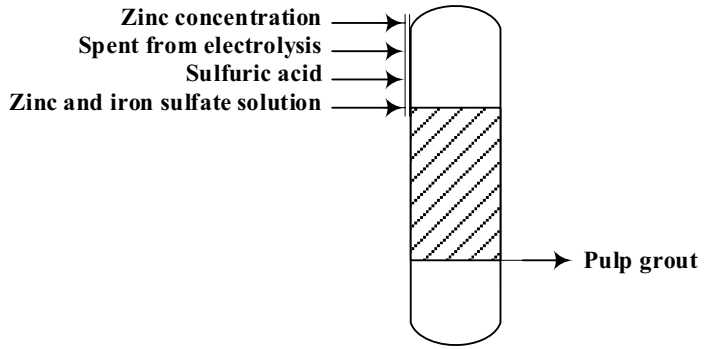

Fig. 2 Inputs and outputs of pulp making

\subsection{Data mining}

Today, there is a strong tendency to directly analyze data without first principles [38]. There is big data in computers, networks, government agencies, businesses, etc., but a small amount is used because it is tough to manage big data. It is also hard to perform efficient and effective analyzes, and meanwhile, the complexity of the data structure is high. The ability to extract hidden information from the data and turn it into knowledge is one of the needs of today's competitive world. The process of using computerbased methods to extract knowledge from data is called

"Zn concentration of acid grout" = $f$ ("thezinc content of concentration", "concentration weight",

"concentration moisture content", " $\mathrm{pH}$ of acid grout", " $\mathrm{H}^{+}$concentration of acid grout",

"Zn content of electrolysis spent", " $\mathrm{H}^{+}$of electrolysis spent", "weight of Sulfuric acid input to pulp",

"zinc concentration of zinc and iron sulfate solution", and " $\mathrm{H}^{+}$concentration of zinc and iron sulfate solution input to pulp")

To monitor this operation and access the data, the operation was continuously monitored in three shifts in 31 working days. During this period, 372 data related to processing input and output variables were extracted according to Eq. (1). Average calculations have been applied to use the supervising control and data acquisition (SCADA) system. data mining [39].

The main methods of data mining are divided into two categories [40]

(i) Descriptive Descriptive tasks define the general properties of data. The purpose of the description is to find patterns about data that can be interpreted by humans. 
Table 3 The input and output variables of pulp making and their measurement status

\begin{tabular}{|c|c|c|c|c|c|c|c|}
\hline & Variables & $\begin{array}{l}\text { Measure- } \\
\text { ment } \\
\text { status }\end{array}$ & Unit & & Variables & $\begin{array}{l}\text { Measure- } \\
\text { ment } \\
\text { status }\end{array}$ & Unit \\
\hline \multirow[t]{12}{*}{ Inputs } & The zinc content of concentration & Ok & $\%$ & Outputs & $\begin{array}{l}\text { Zn concentration of acid } \\
\text { leach output }\end{array}$ & Ok & $\mathrm{gr} / \mathrm{lit}$ \\
\hline & Concentration weight & Ok & $\mathrm{kg}$ & & $\mathrm{pH}$ of acid leach output & Ok & - \\
\hline & Concentration moisture content & Ok & $\%$ & & & & \\
\hline & Zn content of electrolysis spent & Ok & gr/lit & & & & \\
\hline & $\mathrm{H}^{+}$of electrolysis spent & Ok & gr/lit & & & & \\
\hline & $\mathrm{Pb}$ content of electrolysis spent & Ok & ppm & & & & \\
\hline & $\mathrm{Cl}$ content of electrolysis spent & Ok & ppm & & & & \\
\hline & Weight of Sulfuric acid & Ok & $\mathrm{kg}$ & & & & \\
\hline & Zn concentration of zinc and iron sulfate solution & Ok & gr/lit & & & & \\
\hline & Fe concentration of zinc and iron sulfate solution & Ok & ppm & & & & \\
\hline & $\mathrm{H}^{+}$concentration of zinc and iron sulfate solution & Ok & gr/lit & & & & \\
\hline & The volume of zinc and iron sulfate solution & Ok & $\mathrm{m}^{3}$ & & & & \\
\hline
\end{tabular}

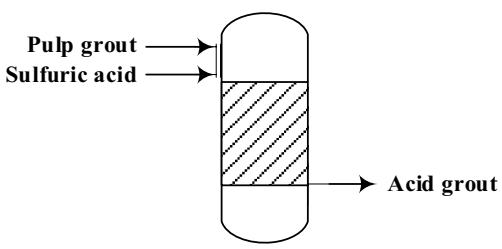

Fig. 3 Inputs and outputs of acid leaching (ii) Predictive Predictive tasks are employed to predict future data behavior.

(iii) Prediction refers to using multiple variables or fields in a database to predict future or unknown values of other interesting variables.

The data mining process can be considered as Fig. 4 [41].

Table 4 The input and output variables of acid leaching and their measurement status

\begin{tabular}{|c|c|c|c|c|c|c|c|}
\hline & Variables & $\begin{array}{l}\text { Measure- } \\
\text { ment status }\end{array}$ & Unit & & Variables & $\begin{array}{l}\text { Measure- } \\
\text { ment status }\end{array}$ & Unit \\
\hline \multirow[t]{5}{*}{ Inputs } & Zn concentration of pulp grout & Ok & $\mathrm{gr} / \mathrm{lit}$ & Outputs & Zn concentration of acid grout & Ok & $\mathrm{gr} / \mathrm{lit}$ \\
\hline & $\mathrm{pH}$ of pulp grout & Ok & - & & $\mathrm{pH}$ of acid grout & Ok & - \\
\hline & Weight of Sulfuric acid & Not ok & - & & Fe concentration of acid grout & Ok & $\mathrm{ppm}$ \\
\hline & & & & & Mn concentration of acid grout & Ok & Ppm \\
\hline & & & & & $\mathrm{H}^{+}$concentration of acid grout & Ok & gr/lit \\
\hline
\end{tabular}

Fig. 4 Data mining process

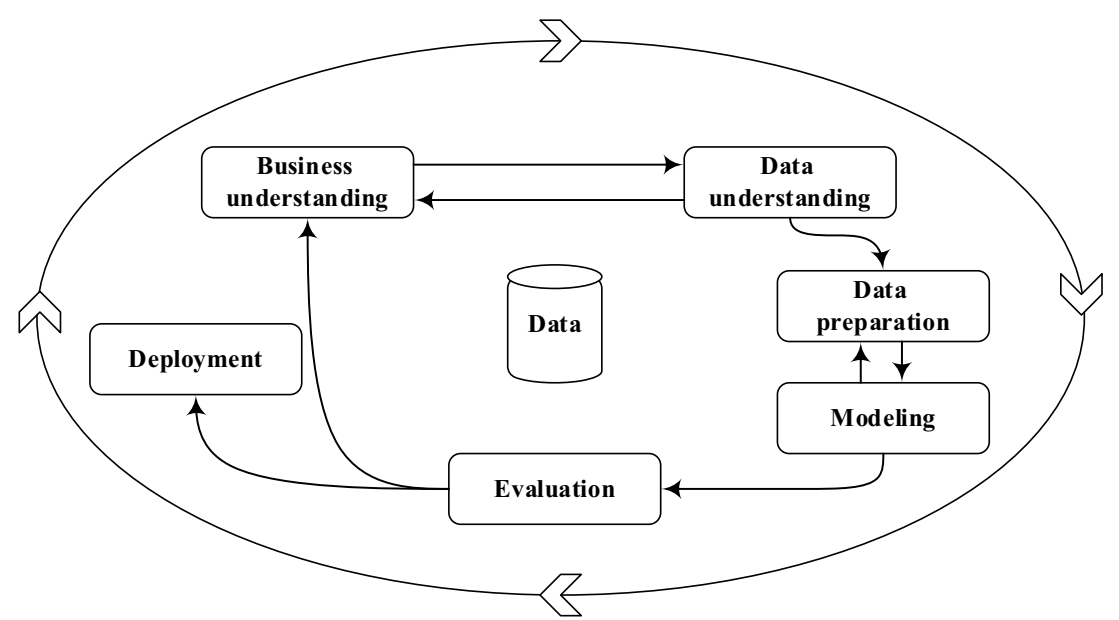

SN Applied Sciences 
Statistics is the science of collecting and organizing data and drawing conclusions from data sets. Statistical data analysis is one of the best methods for data mining. Statistics provide a diverse set of methods for data mining, including regression [38]. The regression method used in this paper is described below.

\subsection{Regression}

Regression analysis is a statistical technique for modeling relationships between variables [42]. If $y$ is a dependent variable and $x$ is an independent variable, then the simple linear regression model is as:

$y=\beta_{\circ}+\beta_{1} x+\varepsilon$

where $\beta_{0}$, is an intercept, $\beta_{1}$ is the line slope, and $\varepsilon$ is the error value, which is assumed to have a normal distribution with a mean of zero and a variance of $\sigma^{2}$.

The general characteristics of the regression model can be controlled by: (i) test of the regression significance, (ii) analysis of variance, and (iii) coefficient of determination [43].

The multiple linear regression model has a dependent variable $(y)$ and $k$ independent variables $\left(x_{1}, x_{2}, \ldots, x_{k}\right)$ as follows:

$y=\beta_{\circ}+\beta_{1} x_{1}+\beta_{2} x_{2}+\cdots+\beta_{k} x_{k}+\varepsilon$

Parameters $\beta_{j} ; j=0,1, \ldots, k$ are called regression coefficients. This model defines a hyperplane in the $k$-dimensional space of independent variables $x_{j}$. One of the major problems that can cause regression models to be ineffective is the multicollinearity or near-linear dependence between the independent variables. One of the multicollinearity identification indexes is the variance inflation factor (VIF), which is described as:

$V I F_{j}=\frac{1}{1-R_{j}^{2}}$

where $R_{j}^{2}$ is the multiple coefficient of determination obtained by fitting the independent variable $x_{j}$ over the other independent variables. Roughly, if VIF $>10$, then it indicates that there is multicollinearity between the independent variables.

\subsubsection{Identifying leverage and influence points}

Outliers Residuals whose absolute values are much larger than others are called outliers. These points are typically different from other points.

Leverage points These are far away in the $x$ space but almost cross the line that passes through the rest.
Influence points These points have unusual values of $x$ and $y$. Common methods for identifying influence points include Cook's D [37], DFFITS, and DFBETAS [44].

A second-order polynomial in two variables regression model as follows:

$y=\beta_{\circ}+\beta_{1} x_{1}+\beta_{2} x_{2}+\beta_{11} x_{1}^{2}+\beta_{22} x_{2}^{2}+\beta_{12} x_{1} x_{2}+\varepsilon$

The parameter $\beta_{12}$ measures the interaction effects between two variables. The above relation is second-order. As a general rule, the lower the order of the regression model, the better.

\subsubsection{Variables selection}

In practical matters, the analyzer usually has the set of candidate independent variables, that among them, the variables required for use in the model should be determined. This is called variable selection, which determines the best regression equation [45].

\subsubsection{Computational techniques for variable selection}

(i) All possible regression In this method, the analyst fits all regression equations, including one independent variable, two independent variables, etc. Then, the best of them is selected based on the evaluation criteria of the regression models.

(ii) Stepwise regression methods To avoid the computational complexity of all possible regression methods, several techniques have been suggested to add and subtract a variable each time of execution. These techniques include forward selection, backward elimination, and stepwise regression.

Forward selection This method assumes no independent variable in the model (except the intercept term). Then each variable is entered into the model one at a time. A variable is selected that has the largest correlation with the dependent variable $(y)$. Similarly, after adding the first independent variable, the other variables are entered. The variable that has the largest correlation with the $y$ variable (after entering the first variable) is selected. Also, the sequence of variables to enter is such that a variable is given the priority that the $F$-statistic value due to entering it into the model is greater than the selected value of the $F$-statistic called $F_{I N}(F$-to-enter). This algorithm stops when the $F$-statistic does not exceed $F_{I N}$.

Backward elimination This method begins with a model in which all variables of the input candidate ( $k$ variables) exist in the model. The partial $F$-statistic value for each of the independent variables, so that it is the last variable to enter the model, is then calculated. The smallest partial 
Fig. 5 a Histogram of the $y-$ first interval. $\mathbf{b}$ Histogram of the $y$-second interval $\mathbf{a}$ Summary Report for $Y$

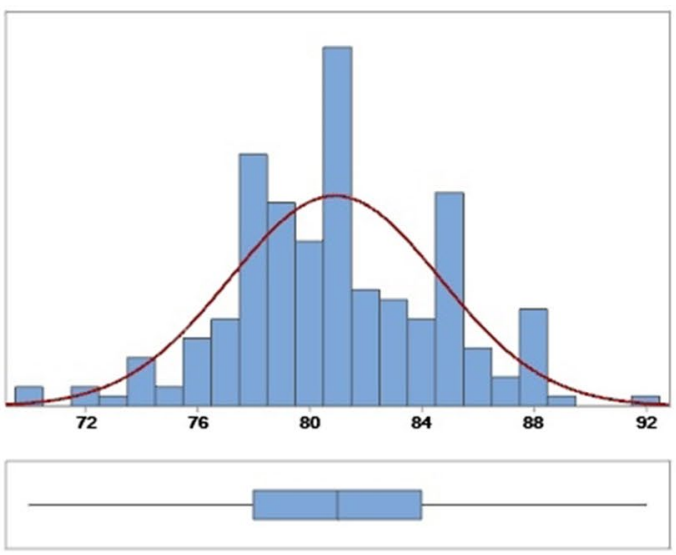

95\% Confidence Intervals

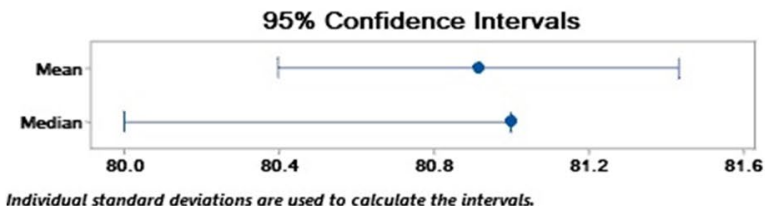

Summary Report for $Y$

b
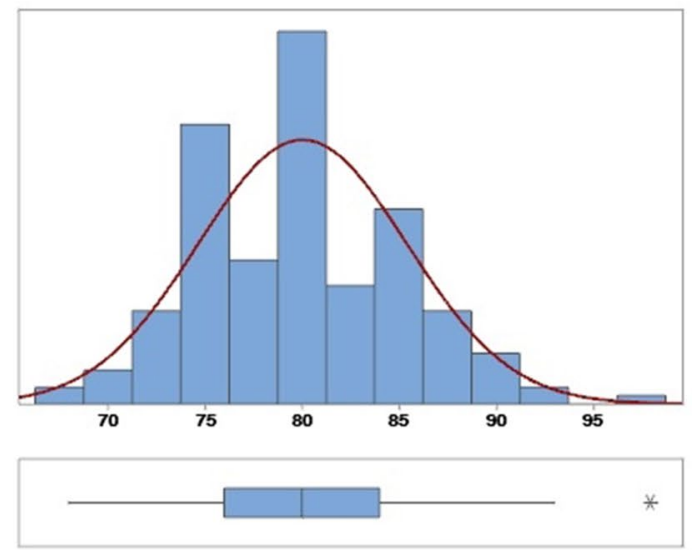

95\% Confidence Intervals

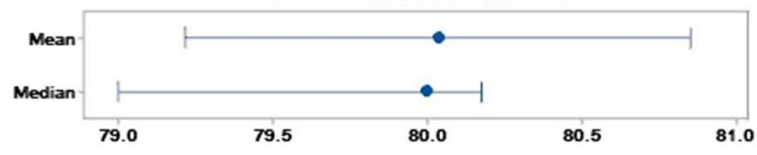

Individual standard deviations are used to calculate the intervals.
Anderson-Darling Normality Test A-Squared $\quad 1.67$ P-Value $\quad<0.005$

Mean $\quad \mathbf{8 0 . 9 1 7}$

StDev $\quad 3.753$

Variance $\quad 14.087$

Skewness $\quad 0.001883$

Kurtosis $\quad 0.203958$

N 204

Minimum $\quad 70.000$

1st Quartile $\quad \mathbf{7 8 . 0 0 0}$

Median $\quad \mathbf{8 1 . 0 0 0}$

3rd Quartile $\quad \mathbf{8 4 . 0 0 0}$

Maximum $\quad 92.000$

95\% Confidence Interval for Mean $\mathbf{8 0 . 3 9 9} \mathbf{8 1 . 4 3 5}$

95\% Confidence Interval for Median

$80.000 \quad 81.000$

95\% Confidence Interval for StDev 3.421 4.158

\begin{tabular}{|cc|}
\hline Anderson-Darling & Normality Test \\
A-Squared & 1.25 \\
P-Value & $<0.005$ \\
\hline Mean & $\mathbf{8 0 . 0 3 6}$ \\
StDev & 5.373 \\
Variance & 28.873 \\
Skewness & 0.315435 \\
Kurtosis & -0.032396 \\
N & 168 \\
\hline Minimum & 68.000 \\
1st Quartile & 76.000 \\
Median & 80.000 \\
3rd Quartile & $\mathbf{8 4 . 0 0 0}$ \\
Maximum & 98.000 \\
\hline 95\% Confidence Interval for Mean \\
79.217 & $\mathbf{8 0 . 8 5 4}$ \\
\hline 95\% Confidence Interval for Median \\
79.000 & $\mathbf{8 0 . 1 7 7}$ \\
95\% Confidence Interval for StDev \\
4.854 & 6.019 \\
\hline
\end{tabular}

F-statistic value is compared with the preselected value called $F_{\text {OUT }}$ (F-to-remove). If it is less than this value, the independent variable is removed from the model. Then the regression model is fitted with $k-1$ independent variables, and this procedure is repeated. This algorithm stops when the smallest partial $F$ is not less than the $F_{\text {OUT }}$.
Stepwise regression This method is a modified version of the forward selection method. At each stage, all independent variables enter a model that has already been re-evaluated by partial $F$-statistic. The independent variable added to the model in the previous step may be redundant at this stage. If the value of the partial $F$-statistic for a variable is 
Table 5 Inputs and outputs notations

\begin{tabular}{|c|c|c|c|c|c|c|c|}
\hline & Variables & Unit & Notation & & Variables & Unit & Notation \\
\hline \multirow[t]{10}{*}{ Inputs } & The zinc content of concentration & $\%$ & $x_{1}$ & Output & $\begin{array}{l}\text { Zn concentration output } \\
\text { of acid leaching }\end{array}$ & gr/lit & $Y$ \\
\hline & Concentration weight & $\mathrm{kg}$ & $x_{2}$ & & & & \\
\hline & Concentration moisture content & $\%$ & $x_{3}$ & & & & \\
\hline & $\mathrm{pH}$ of acid grout & - & $x_{4}$ & & & & \\
\hline & $\mathrm{H}^{+}$concentration of acid grout & $\mathrm{gr} / \mathrm{lit}$ & $x_{5}$ & & & & \\
\hline & Zn content of electrolysis spent & $\mathrm{gr} / \mathrm{lit}$ & $x_{6}$ & & & & \\
\hline & $\mathrm{H}^{+}$of electrolysis spent & $\mathrm{gr} / \mathrm{lit}$ & $x_{7}$ & & & & \\
\hline & Weight of Sulfuric acid input to pulp & $\mathrm{kg}$ & $x_{8}$ & & & & \\
\hline & $\begin{array}{l}\text { Zn concentration of zinc and iron sulfate } \\
\text { solution input to pulp }\end{array}$ & $\mathrm{gr} / \mathrm{lit}$ & $x_{9}$ & & & & \\
\hline & $\begin{array}{l}\mathrm{H}^{+} \text {concentration of zinc and iron sulfate } \\
\text { solution input to pulp }\end{array}$ & $\mathrm{gr} / \mathrm{lit}$ & $x_{10}$ & & & & \\
\hline
\end{tabular}

less than the $F_{\text {OUT, }}$, then it is removed from the model. This method requires two cuts-off values entitled $F_{I N}$ and $F_{\text {OUT }}$.

\subsubsection{Dependent variable optimization}

Dependent variable (y) optimization is used to identify a combination of independent variables that jointly optimize one or more dependent variables. Joint optimization should satisfy the requirements of all dependent variables that are measured by the composite desirability criterion. Individual and composite desirability assesses how a combination of independent variables will satisfy the intended purpose of the dependent variable. Individual desirability $(d)$ also evaluates the desirability of how the settings optimize the dependent variable. Besides, composite desirability $(D)$ evaluates how the settings optimize the set of dependent variables. The value of the desirability has a range between zero and one. One represents the ideal value, and the value of zero means that one or more dependent variables are outside their acceptable range. Minitab software optimizes the dependent variable through a desirability function that is the utility transfer function.

\section{Results and discussion}

The duration of the study is 31 working days. During this period, the type of incoming concentration to the process has been different, so the process has been divided into two periods. The first and second intervals include 17 and 14 working days, respectively.

Pre-processing After collecting the data of the first interval, the missing values, inconsistent and incomplete data were identified and deleted, which finally included 204 data related to the input and output variables. Also, after pre-processing, the second interval had 168 data related to process input and output variables.

Definition of variables According to Sect. 3, the definition of the variables is presented in Table 5 .

Descriptive analysis of process input and output variables After data collection and pre-processing, descriptive analysis is used to describe the data. Table 6 shows the analysis of descriptive statistics of process input and output variables. Figure 5 also shows the histogram of the output variable (y) in the first and second intervals.

Identification of outliers As mentioned in Sect. 3, input and output variables are defined as the following function:

$Y=f\left(x_{1}, x_{2}, \ldots, x_{10}\right)$

To determine the relationship between the input and output variables, the first-order polynomial model was first fitted, which did not show good results. Then, the secondorder polynomial model with interactions was used. It has been shown that the second-order polynomial model with interaction effects is typically valid for chemical process data and is known as an appropriate experimental model for this data [46]. To do this, all independent variables were first standardized (the mean value was subtracted and then divided by standard deviation). To fit this model, the outliers are first extracted. In this paper, Minitab software is used to fit and analyze the model. The software uses three statistics to identify outliers.

i. Leverages Leverages value provides information that can be used to determine whether an observation has an unusual predictor value compared to others or not. This value is measured using the distance between $x$ values of an observation from the mean values of $x$ for all observations. 


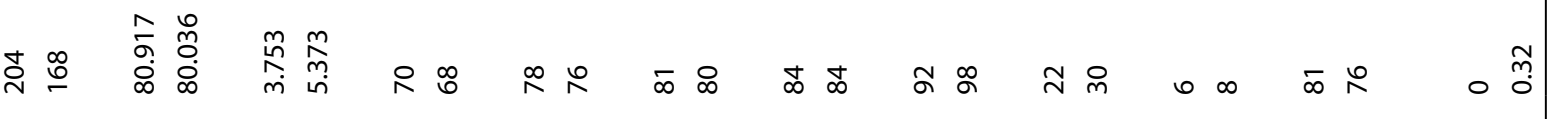
華遂

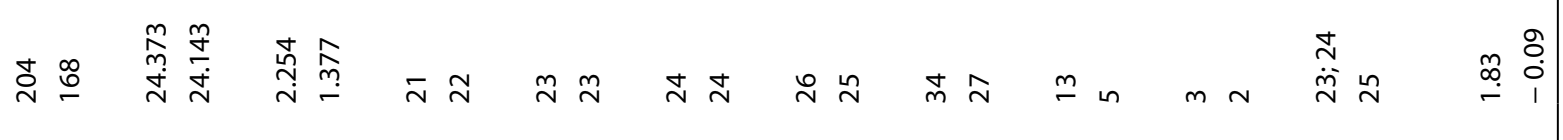

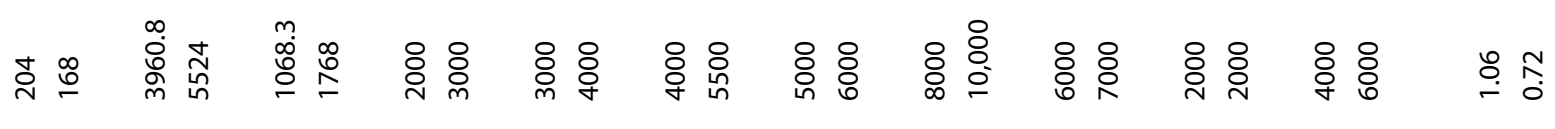

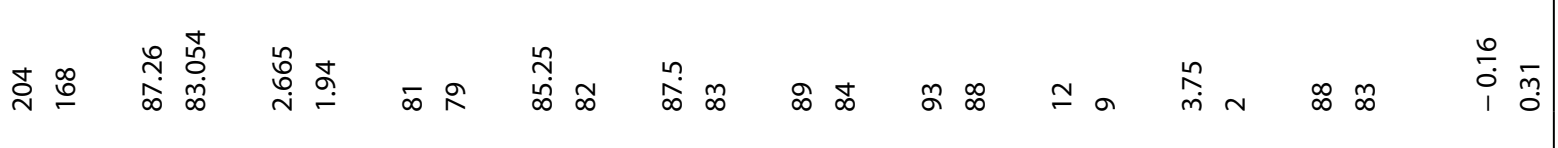

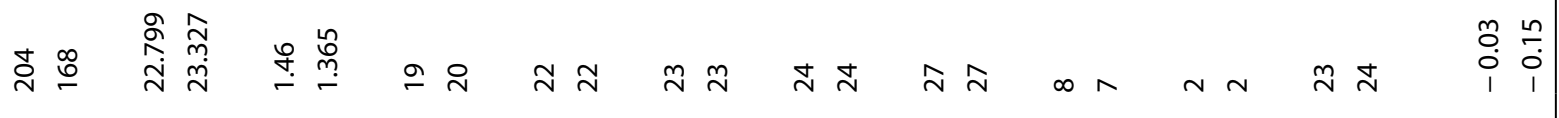

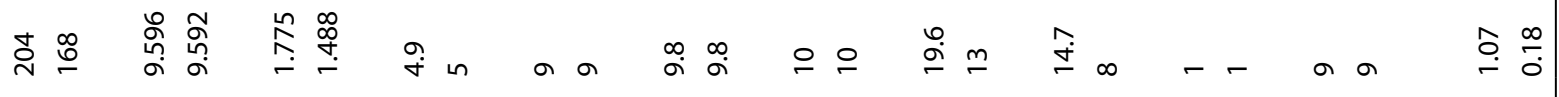

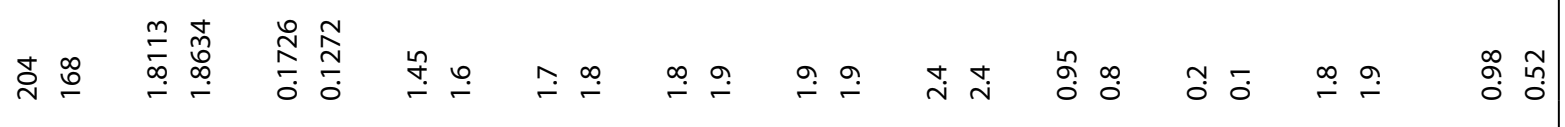

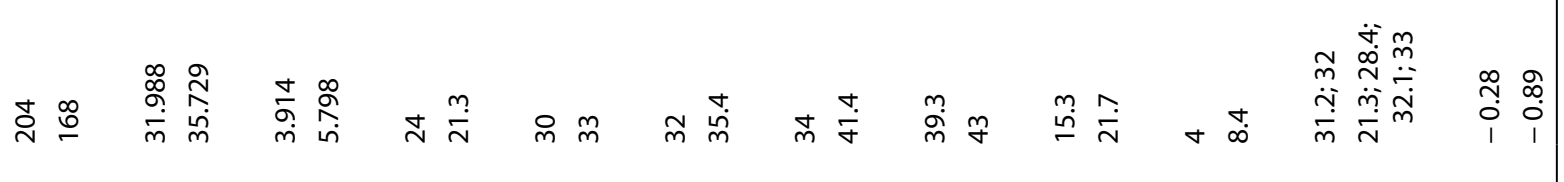

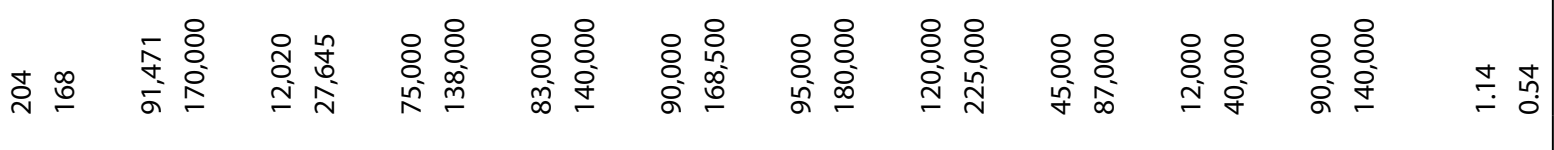

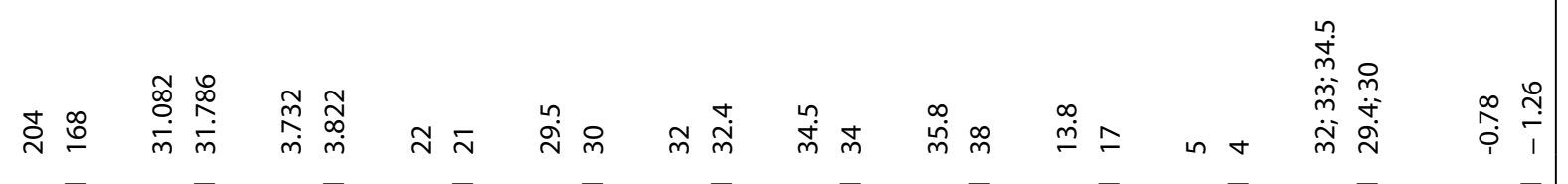

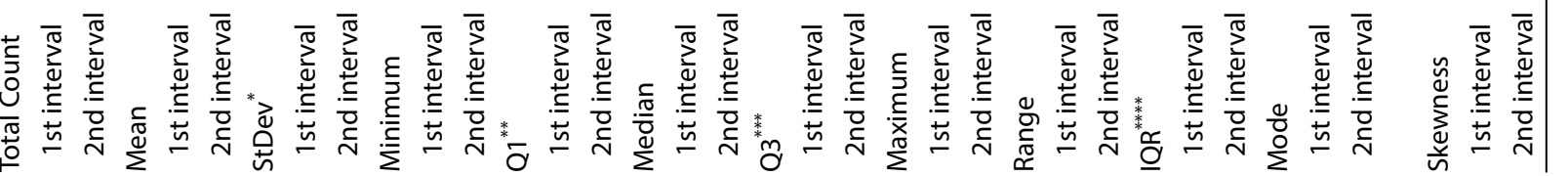




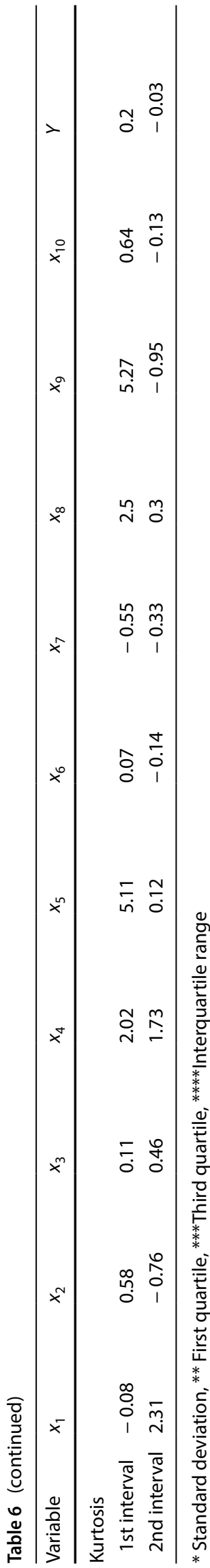

SN Applied Sciences A SPRINGER NATURE journal
Table 7 Results of model fitting on the first interval

\begin{tabular}{llll}
\hline Model Summary & & & \\
\hline S & R-sq & R-sq(adj) & R-sq(pred) \\
\hline 0.964486 & $95.52 \%$ & $91.79 \%$ & $80.94 \%$ \\
\hline
\end{tabular}

ii. Cook's distance This is a general criterion for the combined effect of each observation on the fitted values. This criterion determines whether an observation is unusual due to both $x$ and $y$ values.

iii. DFITS This criterion uses a leverage value and the deleted residuals to calculate the difference between the estimated values with and without considering the $i^{\text {th }}$ observation.

\subsection{First interval}

To fit the model, 180 data were randomly selected to train, and 24 data (about 12\%) are also randomly chosen to test. Accordingly, by fitting the second-order polynomial model with interaction effects, 36 unusual observations were identified and deleted from the data over four stages. With the removal of unusual data, 144 data remained, and the results of the model fitting on the remaining data are shown in Table 7.

Variable selection Stepwise, forward selection, and backward elimination algorithms were used to select the important and effective input variables, and finally, the stepwise algorithm was chosen according to its desirable properties. By applying the stepwise algorithm, the results were obtained in Table 8.

In this model, $R^{2}=80.33$ and $R_{a d j}^{2}=74.65$ that shows good values. Also, the maximum value of VIF is 14.3 , which is almost acceptable (see Table 8). Figure 6 shows the residual plots of the model. As can be seen in this figure, there is no violation of the main assumptions of regression.

Testing the model To test the model, 24 random data were used. Table 9 shows the actual and fitted values of $y$.

The mean absolute error calculated as $M S E=\sum\left|y_{i}-\hat{y}_{i}\right| / N$ is equal to 2.545 , which is acceptable because it is small enough.

Significance analysis According to the $p$ values of Table 8 , it can be seen that some of the variables are significant. It can be concluded that $\mathrm{x}_{3}, \mathrm{x}_{7}, \mathrm{x}_{9}, \mathrm{x}_{10}$, and $\mathrm{x}_{1} \times \mathrm{x}_{2}$ are not significant at the $5 \%$ level. But, since they have significant interaction effects, e.g., $x_{3} \times x_{10}$ is significant and also, concerning the plant experts' opinion, it is decided to keep them in the model. The Pareto diagram of the coefficients' absolute value is depicted in Fig. 7. It can be discussed that three variables of $x_{8} \times x_{9}, x_{5} \times x_{10}$, and $x_{8}$ (about $9 \%$ of the selected variables) impact about $20 \%$ on the model. 
Table 8 Results of the stepwise algorithm on the first interval

\begin{tabular}{|c|c|c|c|c|c|}
\hline \multicolumn{6}{|c|}{ Coefficients } \\
\hline Term & Coef & SE Coef & T-Value & $p$ value & VIF \\
\hline Constant & 83.631 & 0.5 & 167.35 & 0 & \\
\hline$x_{1}$ & -1.537 & 0.469 & -3.28 & 0.001 & 10.93 \\
\hline$x_{2}$ & 1.392 & 0.472 & 2.95 & 0.004 & 11.1 \\
\hline$x_{3}$ & -0.611 & 0.479 & -1.28 & 0.204 & 11.4 \\
\hline $\mathrm{x}_{4}$ & -0.941 & 0.251 & -3.75 & 0 & 3.13 \\
\hline$x_{5}$ & -1.122 & 0.242 & -4.64 & 0 & 2.91 \\
\hline$x_{6}$ & 0.931 & 0.351 & 2.65 & 0.009 & 6.14 \\
\hline$x_{7}$ & 0.376 & 0.283 & 1.33 & 0.187 & 4 \\
\hline$x_{8}$ & 2.158 & 0.371 & 5.82 & 0 & 6.85 \\
\hline$x_{9}$ & 0.159 & 0.349 & 0.46 & 0.649 & 6.05 \\
\hline$x_{10}$ & 0.627 & 0.328 & 1.91 & 0.058 & 5.34 \\
\hline$x_{2}{ }^{*} x_{2}$ & 0.882 & 0.301 & 2.93 & 0.004 & 8.6 \\
\hline$x_{3}{ }^{*} x_{3}$ & -1.214 & 0.278 & -4.37 & 0 & 6.12 \\
\hline$x_{8}^{*} x_{8}$ & -0.965 & 0.142 & -6.79 & 0 & 4.7 \\
\hline$x_{9}^{*} x_{9}$ & -1.122 & 0.202 & -5.56 & 0 & 14.3 \\
\hline$x_{10}{ }^{*} x_{10}$ & 0.321 & 0.146 & 2.2 & 0.03 & 2.54 \\
\hline$x_{1}^{*} x_{2}$ & -0.166 & 0.248 & -0.67 & 0.504 & 6 \\
\hline$x_{1}^{*} x_{7}$ & -1.516 & 0.336 & -4.51 & 0 & 4.62 \\
\hline$x_{1}{ }^{*} x_{9}$ & -1.2 & 0.266 & -4.51 & 0 & 9.86 \\
\hline$x_{2}{ }^{*} x_{8}$ & 1.639 & 0.404 & 4.06 & 0 & 5.18 \\
\hline$x_{2}^{*} x_{10}$ & -0.895 & 0.382 & -2.34 & 0.021 & 5.17 \\
\hline$x_{3}^{*} x_{5}$ & -0.848 & 0.26 & -3.26 & 0.001 & 2.6 \\
\hline$x_{3}{ }^{*} x_{6}$ & -0.808 & 0.241 & -3.35 & 0.001 & 3.99 \\
\hline$x_{3}{ }^{*} x_{8}$ & -1.502 & 0.344 & -4.37 & 0 & 3.87 \\
\hline$x_{3}{ }^{*} x_{10}$ & -1.118 & 0.333 & -3.36 & 0.001 & 7.33 \\
\hline$x_{4}^{*} x_{8}$ & 1.024 & 0.254 & 4.03 & 0 & 2.17 \\
\hline$x_{4}{ }^{*} x_{9}$ & -0.429 & 0.195 & -2.2 & 0.03 & 3.92 \\
\hline$x_{4}^{*} x_{10}$ & 1.79 & 0.414 & 4.32 & 0 & 4.03 \\
\hline$x_{5}^{*} x_{10}$ & 2.227 & 0.402 & 5.54 & 0 & 4.45 \\
\hline$x_{6}^{*} x_{9}$ & -1.346 & 0.281 & -4.8 & 0 & 2.64 \\
\hline$x_{6}^{*} x_{10}$ & 1.097 & 0.322 & 3.41 & 0.001 & 4.71 \\
\hline$x_{8}^{*} x_{9}$ & -2.803 & 0.507 & -5.53 & 0 & 6.43 \\
\hline $\mathrm{x}_{8}{ }^{*} \mathrm{x}_{10}$ & 1.224 & 0.353 & 3.46 & 0.001 & 4.12 \\
\hline \multicolumn{6}{|c|}{ Model Summary } \\
\hline$S$ & $R-s q$ & $R-s q(a d j)$ & R-sq(pr & & \\
\hline 1.6948 & $80.33 \%$ & $74.65 \%$ & $69.30 \%$ & & \\
\hline \multicolumn{6}{|c|}{ Regression Equation } \\
\hline \multicolumn{6}{|c|}{$\begin{array}{c}Y=83.631-1.537 x_{1}+1.392 x_{2}-0.611 x_{3}-0.941 x_{4}-1.122 \\
0.931 x_{6}+0.376 x_{7}+2.158 x_{8}+0.159 x_{9}+0.627 x_{10}+0.882 \\
{ }^{*} x_{2}-1.214 x_{3}{ }^{*} x_{3}-0.965 x_{8}{ }^{*} x_{8}-1.122 x_{9}{ }^{*} x_{9}+0.321 x_{10}{ }^{*} \\
x_{10}-0.166 x_{1}{ }^{*} x_{2}-1.516 x_{1}{ }^{*} x_{7}-1.200 x_{1}{ }^{*} x_{9}+1.639 x_{2}{ }^{*} \\
x_{8}-0.895 x_{2}{ }^{*} x_{10}-0.848 x_{3}{ }^{*} x_{5}-0.808 x_{3}{ }^{*} x_{6}-1.502 x_{3}{ }^{*} \\
x_{8}-1.118 x_{3}{ }^{*} x_{10}+1.024 x_{4}{ }^{*} x_{8}-0.429 x_{4}{ }^{*} x_{9}+1.790 x_{4}{ }^{*} \\
x_{10}+2.227 x_{5}{ }^{*} x_{10}-1.346 x_{6}{ }^{*} x_{9}+1.097 x_{6}{ }^{*} x_{10}-2.803 x_{8}{ }^{*} \\
x_{9}+1.224 x_{8}{ }^{*} x_{10}\end{array}$} \\
\hline
\end{tabular}

Optimization To optimize, according to the process control plan and also to check the range of output values, there is an intention to maximize the concentration of outlet leaching acid. In the first interval, this amount is considered to be $92 \mathrm{~g}$ per liter. Accordingly, using Minitab software, process optimization was performed, and the result is depicted in Table 10.

Figure 8 also shows the optimization plot.

As a result, and after de-standardization, the optimal values of the input variables in the first interval are as Table 11:

\subsection{Second interval}

To fit the model in the second interval, out of 168 data, 156 data are randomly considered for training, and 12 data (about 7\%) were randomly noticed to test the model. So, by fitting the second-order polynomial model with the interaction effects, a total of 18 unusual observations were identified and removed from the data set during two steps. With the remaining 138 data, the result of model fitting is as Table 12.

Variable Selection By applying stepwise, forward selection, and backward elimination algorithms and finally using the stepwise algorithm, the results were obtained as Table 13.

Compared to the first interval, it can be seen that the fitted model of the first interval is better than the second one. Figure 9 shows the residual diagram of the model, which does not offer any deviation from the classical regression assumptions.

Testing the model 12 randomly selected data were used to test the model. The results of the actual and fitted $y$ values are as Table 14. Also, the mean absolute error is 6.47, which is small enough to be acceptable. Compared to the first interval, the fitted model in the second interval has a higher mean absolute error.

Significance analysis Considering the $p$ values of Table 13, $\mathrm{x}_{3}, \mathrm{x}_{4}, \mathrm{x}_{6}, \mathrm{x}_{1} \times \mathrm{x}_{6}, \mathrm{x}_{3} \times \mathrm{x}_{8}, \mathrm{x}_{3} \times \mathrm{x}_{10}, \mathrm{x}_{4} \times \mathrm{x}_{10}, \mathrm{x}_{5} \times \mathrm{x}_{8}$ and $x_{7} \times x_{10}$ are not significant at the $10 \%$ level. According to the fact that they have significant interaction effects, for example, $x_{3} \times x_{4}$ is significant and also, concerning the plant experts' opinion, it is decided to keep them in the model. The Pareto diagram of the coefficients' absolute value is shown in Fig. 10. It can be concluded that three variables of $x_{3} \times x_{4}, x_{2} \times x_{9}$, and $x_{3} \times x_{5}$ (about $10 \%$ of the selected variables) impact about $20 \%$ on the model.

Optimization Based on the control plan and the range of output values of the process, to maximize the output variable, this value was set at $Y=92 \mathrm{gr} /$ lit. Thus, the Minitab software output for optimizing the process is as Table 15.

The optimization plot is also depicted in Fig. 11.

Therefore, after de-standardization, the optimal values of the input variables in the second interval are shown in Table 16: 


\section{Residual Plots for $Y$}
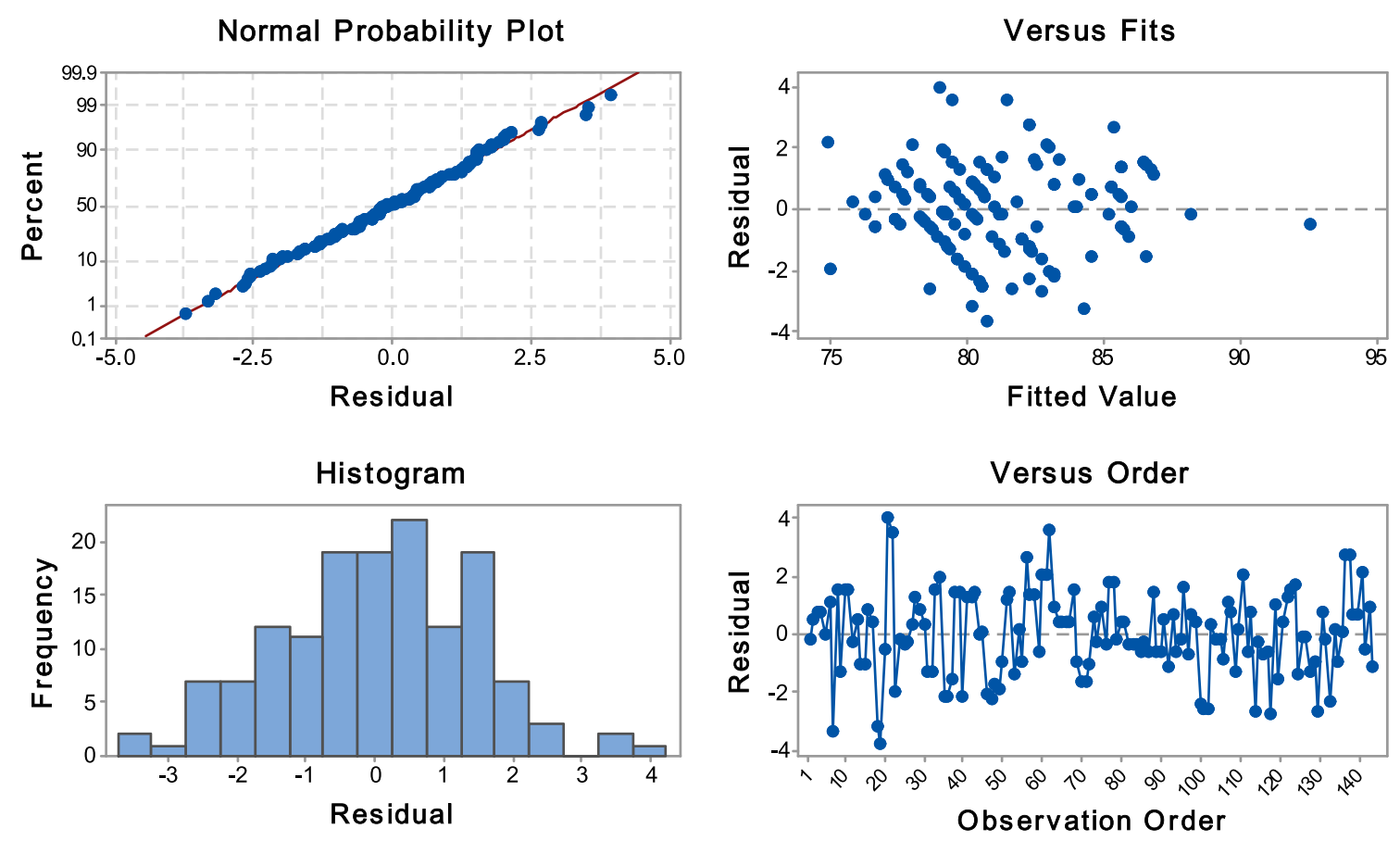

Fig. 6 Residual plots in model fitting for the first interval

Table 9 Testing the model for the first interval

\begin{tabular}{llllll}
\hline$\#$ & Actual $Y$ & Fitted $Y$ & $\#$ & Actual $Y$ & Fitted $Y$ \\
\hline 1 & 86 & 82.85627 & 13 & 78 & 80.86864 \\
2 & 82 & 83.12384 & 14 & 80 & 81.11903 \\
3 & 79 & 82.50931 & 15 & 82 & 82.39476 \\
4 & 79 & 81.54782 & 16 & 82 & 81.35136 \\
5 & 83 & 80.2019 & 17 & 79 & 76.97744 \\
6 & 85 & 80.15319 & 18 & 83 & 78.50269 \\
7 & 81 & 78.7112 & 19 & 80 & 80.46638 \\
8 & 81 & 78.7112 & 20 & 80 & 79.18286 \\
9 & 83 & 81.14842 & 21 & 83 & 84.42712 \\
10 & 84 & 77.25695 & 22 & 88 & 84.31009 \\
11 & 83 & 78.06286 & 23 & 85 & 83.62993 \\
12 & 83 & 78.10629 & 24 & 85 & 84.21374 \\
\hline
\end{tabular}

\subsection{Comparative analysis}

Chemical processes typically have many parameters, and the statistical regression method was widely used for modeling. One of the challenges of using regression methods is the existence of linear dependence between independent variables. This problem, known as multicollinearity, does not affect model interpolation but creates difficulties for extrapolation. Due to the high linear dependence between independent variables in chemical processes, extrapolation isn't performed accurately. In this paper, the proposed model not only can be used for interpolation but also allow accurate extrapolation. The variance inflation factor (VIF) is used for measuring multicollinearity. If VIF $>10$, then it is said that the multicollinearity is strong.

According to Table 8 for the first interval and Table 13 for the second interval, the maximum VIF is 14.3 and 13.95, respectively. These values are relatively acceptable, and it means that the fitted models can be used for interpolation and extrapolation. If the classical regression model is fitted ignoring the interaction effects between variables, i.e., without applying the proposed variable selection, the maximum VIF value is calculated as 122,004 .4. According to the high value of the maximum VIF, it means that the fitted model cannot be used for extrapolation.

Besides, this paper presents a step-by-step data miningbased approach to optimize the chemical processes output. These steps include identifying leverage and influence points, variable selection through stepwise, forward, and backward selection, and dependent variable optimization. 


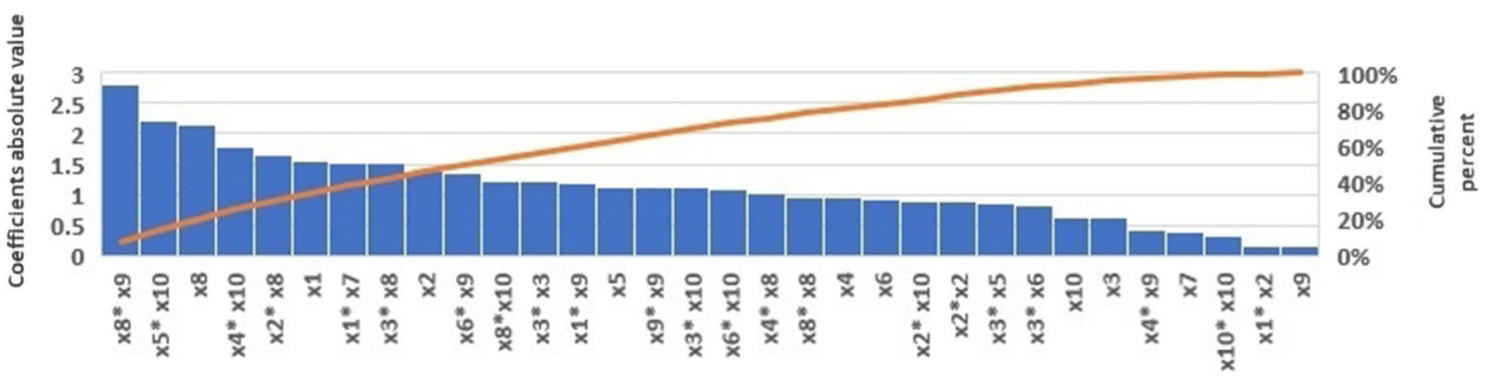

Variables

Fig. 7 The Pareto diagram of the coefficients' absolute value for the first interval

These consecutive steps are the added value of this paper compared with other similar works.

Table 10 Input settings for the first interval

\begin{tabular}{lr}
\hline \multicolumn{2}{l}{ Multiple response prediction } \\
\hline Variable & \multicolumn{1}{c}{ Setting } \\
\hline $\mathrm{x}_{1}$ & 1.34187 \\
$\mathrm{x}_{2}$ & 2.12916 \\
$\mathrm{x}_{3}$ & -1.79051 \\
$\mathrm{x}_{4}$ & -1.94618 \\
$\mathrm{x}_{5}$ & -2.35854 \\
$\mathrm{x}_{6}$ & -2.32767 \\
$\mathrm{x}_{7}$ & -2.44678 \\
$\mathrm{x}_{8}$ & 3.56145 \\
$\mathrm{x}_{9}$ & -1.34378 \\
$\mathrm{x}_{10}$ & 1.98179 \\
\hline
\end{tabular}

\subsection{Discussion}

According to Tables 8 and 13 , in the first interval, in addition to the observed input variables, the second-order variables $x_{2}^{2}, x_{3}^{2}, x_{8}^{2}, x_{9}^{2}$, and $x_{10}^{2}$, and in the second interval, in addition to the observed input variables, the second-order variable $x_{2}^{2}$ is also important. Besides, in the first interval, there is a significant interaction between the following variables:

$x_{1} \times x_{2}, x_{1} \times x_{7}, x_{1} \times x_{9}, x_{2} \times x_{8}, x_{2} \times x_{10}, x_{3} \times x_{5}, x_{3} \times$

$x_{6}, x_{3} \times x_{8}, x_{3} \times x_{10}, x_{4} \times x_{8}, x_{4} \times x_{9}, x_{4} \times x_{10}, x_{5} \times x_{10}$ ，

$x_{6} \times x_{9}, x_{6} \times x_{10}, x_{8} \times x_{9}, x_{8} \times x_{10}$

In the second interval, the following interactions are also important:

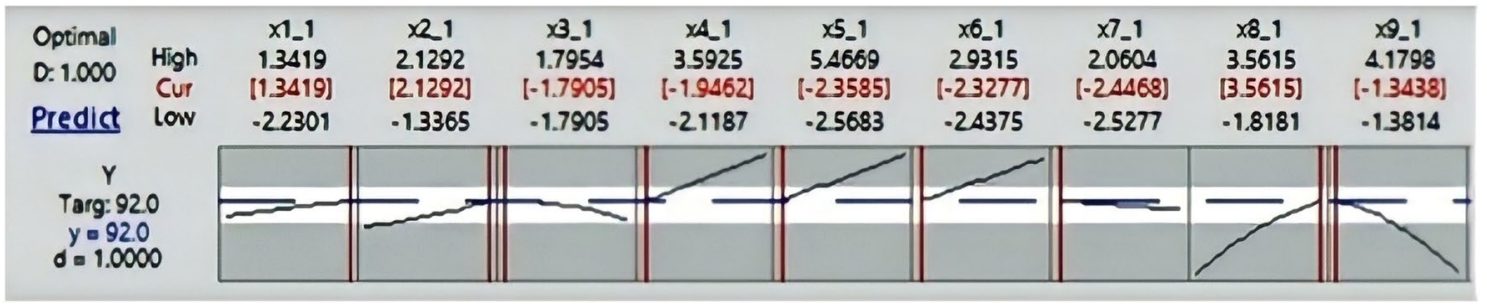

Fig. 8 Optimization plot for the first interval

Table 11 Inputs setting for the first interval

\begin{tabular}{|c|c|c|c|c|c|}
\hline Input variables & Unit & Setting & Input variables & Unit & Setting \\
\hline The zinc content of concentration & $\%$ & 35 & Zn content of electrolysis spent & gr/lit & 19.1 \\
\hline Concentration weight & $\mathrm{kg}$ & 120,000 & $\mathrm{H}^{+}$of electrolysis spent & gr/lit & 81.2 \\
\hline Concentration moisture content & $\%$ & 24 & Weight of Sulfuric acid input to the pulp & $\mathrm{kg}$ & 8,000 \\
\hline $\mathrm{pH}$ of acid grout & - & 1.48 & $\begin{array}{l}\text { Zn concentration of zinc and iron sulfate solu- } \\
\text { tion input to the pulp }\end{array}$ & $\mathrm{gr} / \mathrm{lit}$ & 21 \\
\hline $\mathrm{H}^{+}$concentration of acid grout & gr/lit & 5.3 & $\begin{array}{l}\mathrm{H}^{+} \text {concentration of zinc and iron sulfate solu- } \\
\text { tion input to the pulp }\end{array}$ & $\mathrm{gr} / \mathrm{lit}$ & 113.6 \\
\hline
\end{tabular}


Table 12 Results of model fitting on the second interval

Model Summary

\begin{tabular}{llll}
\hline S & R-sq & R-sq(adj) & R-sq(pred) \\
\hline 2.09206 & $90.68 \%$ & $82.26 \%$ & $59.57 \%$ \\
\hline
\end{tabular}

Table 13 Results of the stepwise algorithm on the second interval

\begin{tabular}{|c|c|c|c|c|c|}
\hline \multicolumn{6}{|c|}{ Coefficients } \\
\hline Term & Coef & SE Coef & T-Value & $p$ value & VIF \\
\hline Constant & 80.6 & 0.585 & 137.68 & 0 & \\
\hline $\mathrm{x}_{1}$ & 3.68 & 1.07 & 3.45 & 0.001 & 13.95 \\
\hline$x_{2}$ & -4.169 & 0.865 & -4.82 & 0 & 9.15 \\
\hline$x_{3}$ & -0.015 & 0.928 & -0.02 & 0.987 & 10.51 \\
\hline $\mathrm{x}_{4}$ & -0.003 & 0.552 & -0.01 & 0.995 & 3.72 \\
\hline$x_{5}$ & 1.753 & 0.584 & 3 & 0.003 & 4.16 \\
\hline$x_{6}$ & -0.196 & 0.511 & -0.38 & 0.702 & 3.19 \\
\hline$x_{7}$ & 0.931 & 0.494 & 1.89 & 0.062 & 2.97 \\
\hline$x_{8}$ & -1.33 & 0.585 & -2.27 & 0.025 & 4.18 \\
\hline$x_{9}$ & 2.561 & 0.573 & 4.47 & 0 & 4.01 \\
\hline$x_{10}$ & 1.844 & 0.558 & 3.3 & 0.001 & 3.81 \\
\hline$x_{2}^{*} x_{2}$ & -4.505 & 0.91 & -4.95 & 0 & 11.38 \\
\hline $\mathrm{x}_{1}{ }^{*} \mathrm{x}_{6}$ & -0.375 & 0.39 & -0.96 & 0.338 & 3.63 \\
\hline$x_{1}{ }^{*} x_{9}$ & -2.94 & 1.06 & -2.78 & 0.006 & 12.02 \\
\hline $\mathrm{x}_{1}{ }^{*} \mathrm{x}_{10}$ & -4.859 & 0.838 & -5.8 & 0 & 5.98 \\
\hline$x_{2}{ }^{*} x_{3}$ & 4.1 & 1.08 & 3.8 & 0 & 9.66 \\
\hline$x_{2}^{*} x_{4}$ & 1.889 & 0.665 & 2.84 & 0.005 & 7.31 \\
\hline$x_{2}^{*} x_{9}$ & 5.255 & 0.88 & 5.97 & 0 & 7.98 \\
\hline$x_{3}{ }^{*} x_{4}$ & -5.55 & 0.81 & -6.86 & 0 & 5.82 \\
\hline$x_{3}{ }^{*} x_{5}$ & -4.98 & 0.758 & -6.57 & 0 & 6.44 \\
\hline$x_{3}{ }^{*} x_{8}$ & 0.063 & 0.608 & 0.1 & 0.917 & 8.67 \\
\hline$x_{3}{ }^{*} x_{9}$ & 2.479 & 0.997 & 2.49 & 0.014 & 10.38 \\
\hline$x_{3}^{*} x_{10}$ & 0.482 & 0.92 & 0.52 & 0.602 & 6.1 \\
\hline$x_{4}^{*} x_{7}$ & -0.98 & 0.468 & -2.09 & 0.039 & 1.78 \\
\hline$x_{4}^{*} x_{9}$ & -1.422 & 0.469 & -3.04 & 0.003 & 4.53 \\
\hline$x_{4}^{*} x_{10}$ & 0.877 & 0.646 & 1.36 & 0.177 & 3.62 \\
\hline$x_{5}{ }^{*} x_{6}$ & 1.118 & 0.457 & 2.45 & 0.016 & 2.43 \\
\hline$x_{5}^{*} x_{8}$ & 0.039 & 0.419 & 0.09 & 0.925 & 2.84 \\
\hline$x_{5}^{*} x_{10}$ & 1.12 & 0.658 & 1.7 & 0.092 & 3.59 \\
\hline$x_{7}^{*} x_{9}$ & -0.891 & 0.392 & -2.27 & 0.025 & 2.41 \\
\hline$x_{7}^{*} x_{10}$ & -0.343 & 0.434 & -0.79 & 0.43 & 2.15 \\
\hline$x_{9} * x_{10}$ & 3 & 0.565 & 5.31 & 0 & 3.16 \\
\hline \multicolumn{6}{|c|}{ Model Summary } \\
\hline $\mathrm{S}$ & R-sq & R-sq(adj) & R-sq(pred) & & \\
\hline 3.34931 & $64.83 \%$ & $54.54 \%$ & $40.41 \%$ & & \\
\hline \multicolumn{6}{|c|}{ Regression Equation } \\
\hline \multicolumn{6}{|c|}{$\begin{array}{l}Y=80.600+3.68 x_{1}-4.169 x_{2}-0.015 x_{3}-0.003 x_{4}+1.753 x_{5}-0 \\
.196 x_{6}+0.931 x_{7}-1.330 x_{8}+2.561 x_{9}+1.844 x_{10}-4.505 x_{2}{ }^{*} \\
x_{2}-0.375 x_{1}{ }^{*} x_{6}-2.94 x_{1}{ }^{*} x_{9}-4.859 x_{1}{ }^{*} x_{10}+4.10 x_{2}{ }^{*} \\
x_{3}+1.889 x_{2}{ }^{*} x_{4}+5.255 x_{2}{ }^{*} x_{9}-5.550 x_{3}{ }^{*} x_{4}-4.980 x_{3} \\
{ }^{*} x_{5}+0.063 x_{3}{ }^{*} x_{8} 1+2.479 x_{3}{ }^{*} x_{9}+0.482 x_{3}{ }^{*} x_{10}-0.980 x_{4}{ }^{*} \\
x_{7}-1.422 x_{4}{ }^{*} x_{9}+0.877 x_{4}{ }^{*} x_{10}+1.118 x_{5}{ }^{*} x_{6}+0.039 x_{5}{ }^{*} \\
x_{8}+1.120 x_{5}{ }^{*} x_{10}-0.891 x_{7}{ }^{*} x_{9}-0.343 x_{7}{ }^{*} x_{10}+3.000 x_{9}{ }^{*} x_{10}\end{array}$} \\
\hline
\end{tabular}

SN Applied Sciences $x_{1} \times x_{6}, x_{1} \times x_{9}, x_{1} \times x_{10}, x_{2} \times x_{3}, x_{2} \times x_{4}, x_{2} \times x_{9}$ ，

$x_{3} \times x_{4}, x_{3} \times x_{5}, x_{3} \times x_{8}, x_{3} \times x_{9}, x_{3} \times x_{10}, x_{4} \times x_{7}$ ，

$x_{4} \times x_{9}, x_{4} \times x_{10}, x_{5} \times x_{6}, x_{5} \times x_{8}, x_{5} \times x_{10}, x_{7} \times x_{9}$ ，

$x_{7} \times x_{10}, x_{9} \times x_{10}$

In the first interval, $x_{5} \times x_{10}$ and in the second interval, $x_{2} \times x_{9}$ have the most positive effects on the output. Also, in the first interval, $x_{8} \times x_{9}$ and in the second interval, $x_{3} \times x_{4}$ have the most negative effects on the output (see Tables 8 and 13).

Table 17 shows the range of changes in process input variables.

Since the input variables can be divided into two parts, including adjustable and unadjustable, the ranges were introduced for process settings, as Table 18. It should be noted the variables that can't be adjusted include: $Z n$ concentration of zinc and iron sulfate solution input to the pulp, $\mathrm{H}^{+}$concentration of zinc and iron sulfate solution input to the pulp, $\mathrm{Zn}$ content of electrolysis spent, and $\mathrm{H}^{+}$ of electrolysis spent.

Results validation: To validate the results, the variable settings of the first interval are used because it is more accurate. The output of the process is examined in two periods before and after the variable settings. Accordingly, 36 samples are extracted before and after the changes. Table 19 shows their descriptive statistics of $Y$.

Statistical hypothesis testing is used to investigate whether there is a significant difference between the mean value of output before and after the changes.

To test the equal variance, the Bonett and Levenes' methods are used. The null hypothesis is considered as $H_{\circ}: \sigma_{1} / \sigma_{2}=1$ with the significant level of $a=5 \%$. Table 20 shows the ratio of the standard deviation. Also, the test results are depicted in Table 21. Figure 12 shows the graphical results.

From Table 21, it can be concluded that the $p$ value is 0.193 and 0.308 for Bonett and Levene's tests, respectively. So, the equal variance hypothesis can't be rejected.

Then, for comparing the mean values, the null hypothesis $H_{\circ}: \mu_{\text {After }}-\mu_{\text {Before }} \geq 0$ is considered. The $p$-value of the hypothesis test is calculated as 0.994 , which means the null hypothesis can't be rejected. Figure 13 shows the individual values before and after parameter settings. These adjustments in the process showed that the $\mathrm{Zn}$ concentration on the process output increased significantly.

Managerial insight In this paper, a chemical process with complex interactions was studied. Managers can use the presented approach of this paper and monitor the process output. Besides, important variables with their interaction effects can also be identified and prioritized.

Limitations of research Data gathering is one of the limitations. Reliable data will lead to relevant results. 


\section{Residual Plots for $\mathrm{Y}$}
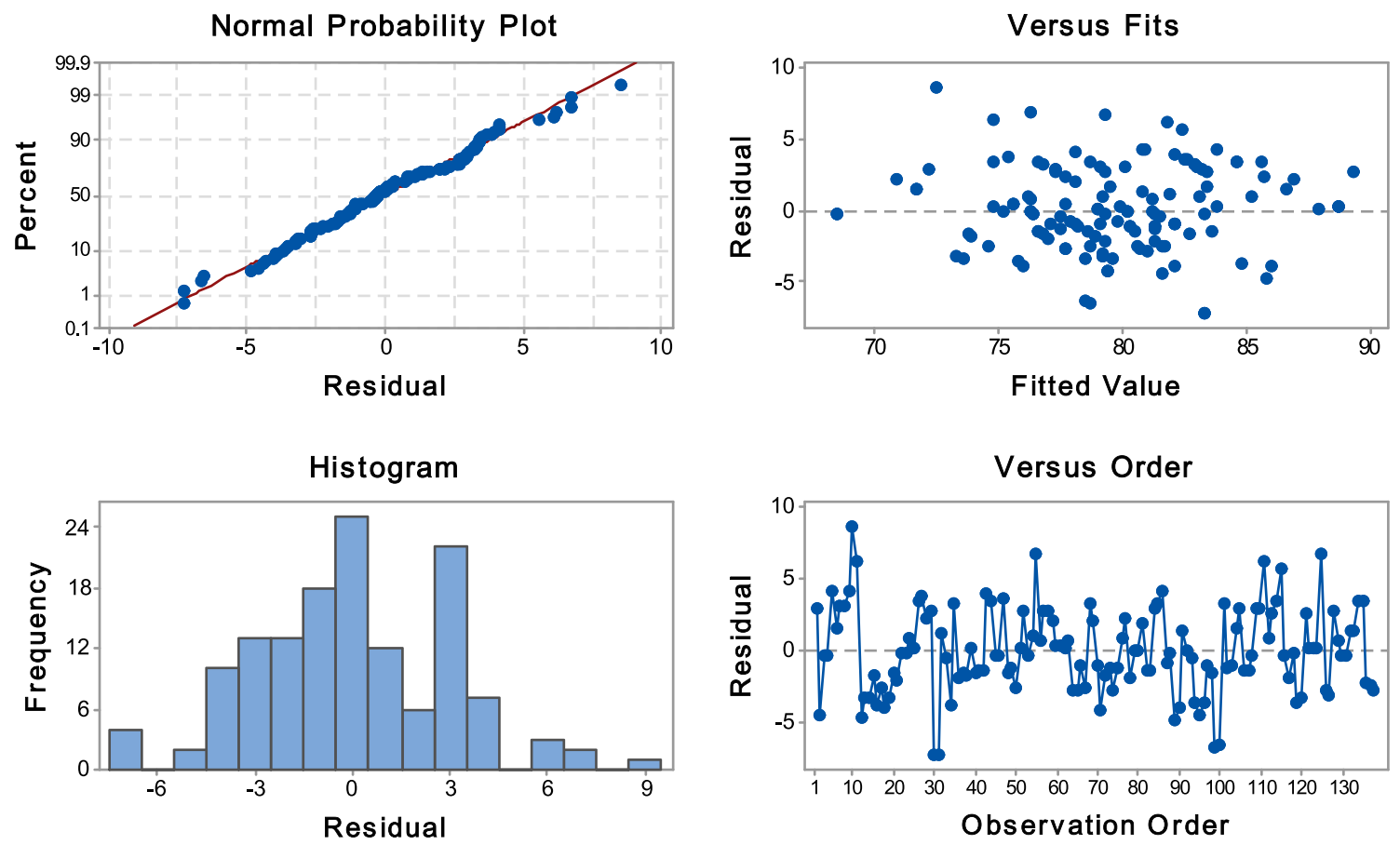

Fig. 9 Residual plots in model fitting for the second interval

Table 14 Testing the model for the second interval

\begin{tabular}{llllll}
\hline$\#$ & ActualY & Fitted $Y$ & $\#$ & Actual $Y$ & Fitted $Y$ \\
\hline 1 & 86 & 86.19265 & 7 & 79 & 79.0352 \\
2 & 75 & 88.94668 & 8 & 79 & 79.0352 \\
3 & 70 & 91.9557 & 9 & 83 & 82.98059 \\
4 & 70 & 92.47163 & 10 & 81 & 90.74395 \\
5 & 75 & 79.0352 & 11 & 86 & 88.5907 \\
6 & 80 & 79.0352 & 12 & 86 & 87.67918 \\
\hline
\end{tabular}

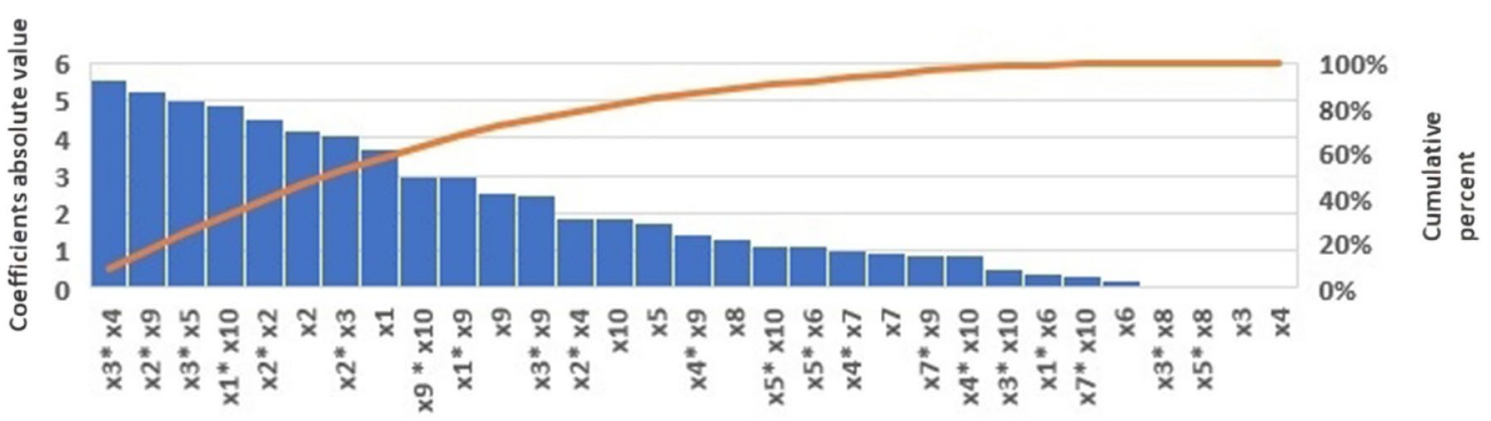

Variables

Fig. 10 The Pareto diagram of the coefficients' absolute value for the second interval 
Table 15 Input settings for the second interval

\begin{tabular}{lc}
\hline \multicolumn{2}{l}{ Multiple response prediction } \\
\hline Variable & \multicolumn{1}{c}{ Setting } \\
\hline $\mathrm{x}_{1}$ & 1.50596 \\
$\mathrm{x}_{2}$ & -1.08521 \\
$\mathrm{x}_{3}$ & -2.59317 \\
$\mathrm{x}_{4}$ & -1.90707 \\
$\mathrm{x}_{5}$ & 2.21141 \\
$\mathrm{x}_{6}$ & 2.70574 \\
$\mathrm{x}_{7}$ & 2.65976 \\
$\mathrm{x}_{8}$ & -1.40749 \\
$\mathrm{x}_{9}$ & 2.0955 \\
$\mathrm{x}_{10}$ & -1.31336 \\
\hline
\end{tabular}

precise data. Then considering different raw materials, the data were divided into two parts. In each part, the stepwise regression method was applied, and the best model fitted the gathered data. The models were checked and verified using MSE. Afterward, to maximize the concentration of outlet leaching acid, the process optimization was performed, and the input settings were extracted. Besides extracted input variables, the second-ordered and interactions were determined. By dividing the input variable into adjustable and unadjustable, the ranges of process settings were introduced. To validate the results, a sample of test data, including before and after variable settings, was taken, and a significant improvement was verified. It was shown that the mean value of the zinc concentration

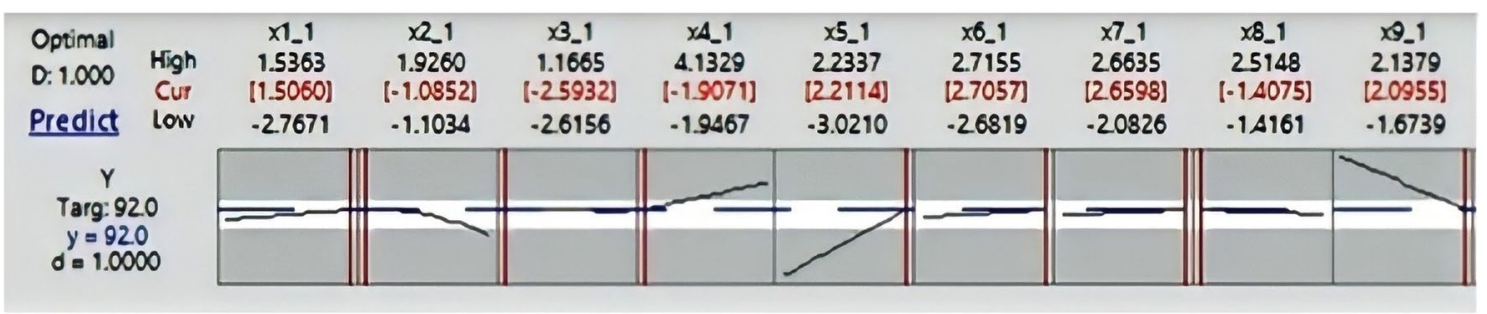

Fig. 11 Optimization plot for the second interval

Table 16 Inputs setting for the second interval

\begin{tabular}{|c|c|c|c|c|c|}
\hline Input variables & Unit & Setting & Input variables & Unit & Setting \\
\hline The Zinc content of concentration & $\%$ & 37.9 & Zn content of electrolysis spent & gr/lit & 27 \\
\hline Concentration weight & $\mathrm{kg}$ & 138,523 & $\mathrm{H}^{+}$of electrolysis spent & gr/lit & 88 \\
\hline Concentration moisture content & $\%$ & 21.4 & Weight of Sulfuric acid input to the pulp & $\mathrm{kg}$ & 3,015 \\
\hline $\mathrm{pH}$ of acid grout & - & 1.6 & $\begin{array}{l}\text { Zn concentration of zinc and iron sulfate solu- } \\
\text { tion input to the pulp }\end{array}$ & gr/lit & 26.9 \\
\hline $\mathrm{H}^{+}$concentration of acid grout & $\mathrm{gr} / \mathrm{lit}$ & 12.9 & $\begin{array}{l}\mathrm{H}^{+} \text {concentration of zinc and iron sulfate solu- } \\
\text { tion input to the pulp }\end{array}$ & gr/lit & 82 \\
\hline
\end{tabular}

Table 17 Tolerance of the input variables

\begin{tabular}{|c|c|c|c|c|c|c|c|c|c|}
\hline \multirow[t]{2}{*}{ Variable } & \multicolumn{2}{|c|}{ First interval } & \multicolumn{2}{|c|}{ Second interval } & \multirow[t]{2}{*}{ Variable } & \multicolumn{2}{|c|}{$\begin{array}{l}\text { First inter- } \\
\text { val }\end{array}$} & \multicolumn{2}{|c|}{$\begin{array}{l}\text { Second } \\
\text { interval }\end{array}$} \\
\hline & Min & Max & Min & Max & & Min & Max & Min & Max \\
\hline Zinc content of concentration & 22 & 35.8 & 21 & 38 & Zn content of electrolysis spent & 19 & 27 & 20 & 27 \\
\hline Concentration weight & 75,000 & 120,000 & 138,000 & 225,000 & $\mathrm{H}+$ of electrolysis spent & 81 & 93 & 79 & 88 \\
\hline Concentration moisture content & 24 & 39.3 & 21.3 & 43 & $\begin{array}{l}\text { weight of Sulfuric acid input to the } \\
\text { pulp }\end{array}$ & 2000 & 8000 & 3000 & 10,000 \\
\hline $\mathrm{pH}$ of acid grout & 1.45 & 2.4 & 1.6 & 2.4 & $\begin{array}{l}\mathrm{Zn} \text { concentration of zinc and iron sul- } \\
\text { fate solution input to the pulp }\end{array}$ & 21 & 34 & 22 & 27 \\
\hline $\mathrm{H}^{+}$concentration of acid grout & 4.9 & 19.6 & 5 & 13 & $\begin{array}{l}\mathrm{H}^{+} \text {concentration of zinc and iron sul- } \\
\text { fate solution input to the pulp }\end{array}$ & 80 & 120 & 82 & 140 \\
\hline
\end{tabular}


Table 18 Final settings of variables

\begin{tabular}{|c|c|c|c|c|}
\hline \multirow{2}{*}{$\frac{\text { Variable }}{\text { Zinc content of concentration }}$} & \multicolumn{2}{|c|}{ First interval } & \multicolumn{2}{|c|}{ Second interval } \\
\hline & 35.8 & (Maximum of the tolerance) & 37.9 & (Maximum of the tolerance) \\
\hline Concentration weight & 120,000 & (Maximum of the tolerance) & 138,523 & (Minimum of the tolerance) \\
\hline Concentration moisture content & 24 & (Minimum of the tolerance) & 21.4 & (Minimum of the tolerance) \\
\hline $\mathrm{pH}$ of acid grout & 1.48 & $\begin{array}{l}\text { (Near to the minimum of the toler- } \\
\text { ance) }\end{array}$ & 1.6 & (Minimum of the tolerance) \\
\hline $\mathrm{H}^{+}$concentration of acid grout & 5.3 & $\begin{array}{l}\text { (Near to the minimum of the toler- } \\
\text { ance) }\end{array}$ & 12.9 & (Near to the maximum of the tolerance) \\
\hline $\begin{array}{l}\text { Weight of Sulfuric acid input to the } \\
\text { pulp }\end{array}$ & 8000 & (Maximum of the tolerance) & 3015 & (Near to the minimum of the tolerance) \\
\hline
\end{tabular}

Table 19 Descriptive analysis for results validation

\begin{tabular}{llll}
\hline Variable & Total Count & Mean & StDev \\
\hline Before & 36 & 80.472 & 3.247 \\
After & 36 & 82.722 & 4.131 \\
\hline
\end{tabular}

Table 20 Ratio of standard deviations

\begin{tabular}{lll}
\hline Estimated Ratio & $\begin{array}{l}95 \% \mathrm{Cl} \text { for Ratio using } \\
\text { Bonett }\end{array}$ & $\begin{array}{l}95 \% \mathrm{Cl} \text { for Ratio using } \\
\text { Levene }\end{array}$ \\
\hline 1.27225 & $(0.865,1.807)$ & $(0.810,1.833)$ \\
\hline
\end{tabular}

output of acid leaching was increased significantly by 2.25 $\mathrm{gr} / \mathrm{lit}$. For future studies, autoregressive models that consider the time delay are recommended.

Table 21 Equality of variance test results

\begin{tabular}{|c|c|c|c|c|}
\hline \multicolumn{4}{|c|}{ Null hypothesis } & $H_{0}: \sigma_{1} / \sigma_{2}=1$ \\
\hline Alternati & & & & $\mathrm{H}_{1}: \sigma_{1} / \sigma_{2} \neq 1$ \\
\hline Significar & & & & $a=0.05$ \\
\hline Method & Test Statistic & DF1 & DF2 & $P$ Value \\
\hline Bonett & 1.70 & 1 & & 0.193 \\
\hline Levene & 1.05 & 1 & 70 & 0.308 \\
\hline
\end{tabular}


Fig. 12 The graphical results of the variance equality test

\section{Test and $\mathrm{Cl}$ for Two Variances: After, Before \\ Ratio $=1$ vs Ratio $\neq 1$}
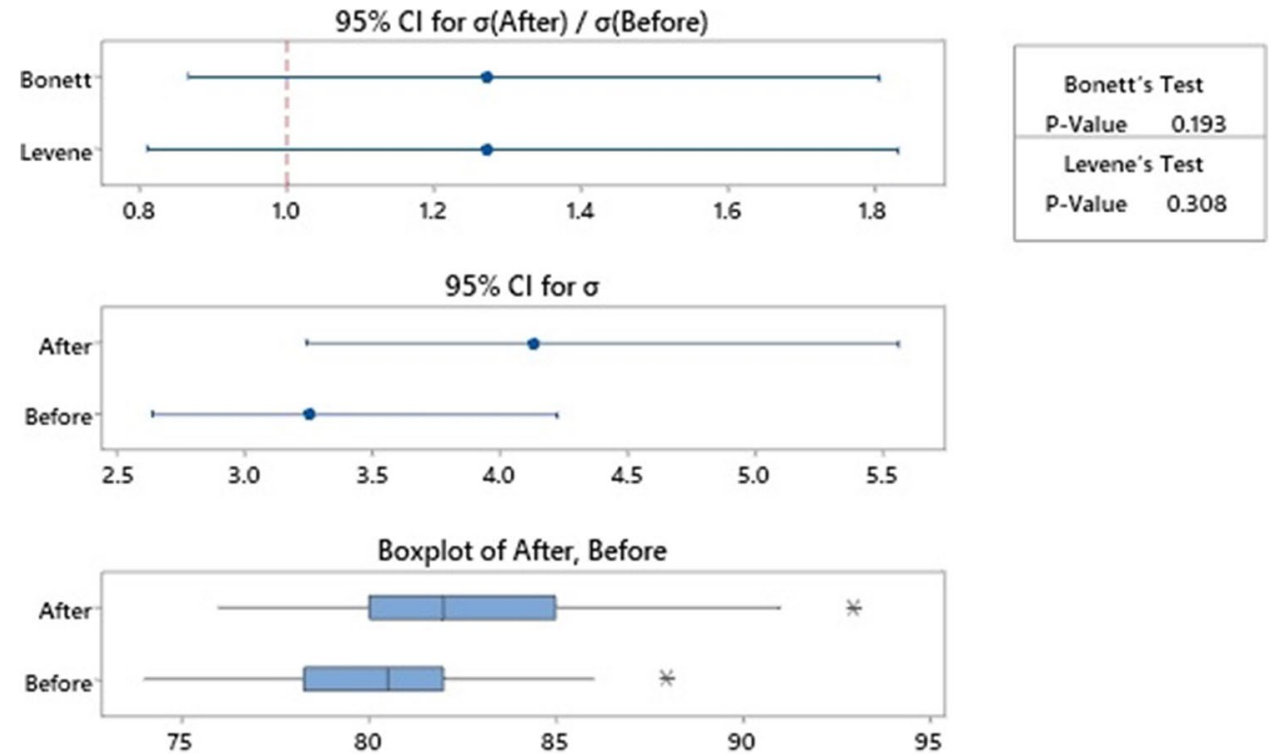

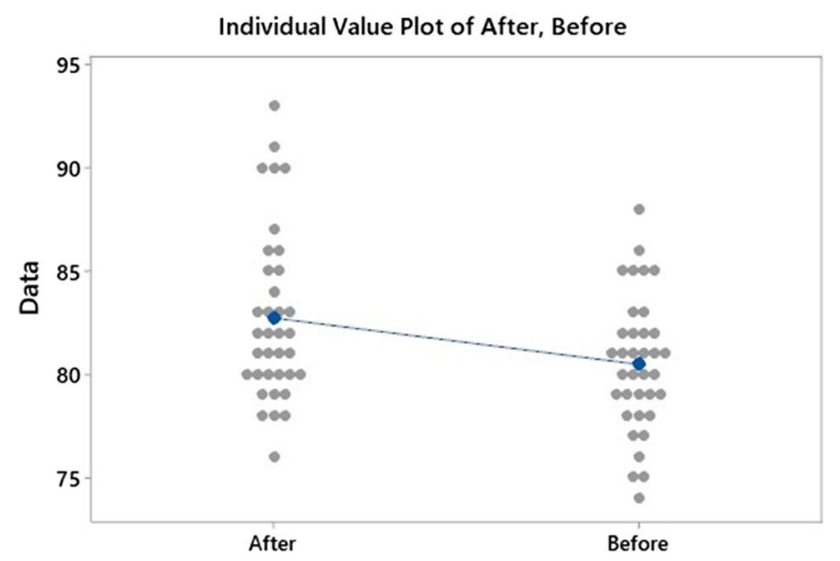

Fig. 13 Individual values before and after parameter settings

Data availability All data generated or analyzed during this study are included in the article.

\section{Compliance with ethical standards}

Conflict of interests The authors declare that they have no competing interests

Open Access This article is licensed under a Creative Commons Attribution 4.0 International License, which permits use, sharing, adaptation, distribution and reproduction in any medium or format, as long as you give appropriate credit to the original author(s) and the source, provide a link to the Creative Commons licence, and indicate if changes were made. The images or other third party material in this article are included in the article's Creative Commons licence, unless indicated otherwise in a credit line to the material. If material is not included in the article's Creative Commons licence and your intended use is not permitted by statutory regulation or exceeds the permitted use, you will need to obtain permission directly from the copyright holder. To view a copy of this licence, visit http://creativecommons. org/licenses/by/4.0/.

\section{References}

1. Shanks W, Kimball B, Tolcin A, Guberman D (2017). Germanium and Indium Chapter I of Critical Mineral Resources of the United States-Economic and Environmental Geology and Prospects for Future Supply. https://doi.org/10.3133/pp1802I.

2. Fortier S, Thomas C, McCullough E, Tolcin A (2017) Global trends in mineral commodities for advanced technologies. Nat Res Res. https://doi.org/10.1007/s11053-017-9340-9

3. Greenwood NN, Earnshaw A (1997) Chemistry of the Elements. Butterworth-Heinemann, Oxford

4. Stwertka A (1998) "Zinc". Guide to the Elements. Oxford University Press, Oxford

5. Emsley J (2001) "Zinc". Nature's Building Blocks: An A-Z Guide to the Elements. Oxford University Press, Oxford, England, UK

6. Bounoughaz M, Salhi E, Benzine K, Ghali E, Dalard F (2003) A comparative study of the electrochemical behaviour of Algerian zinc and a zinc from a commercial sacrificial anode. J Mater Sci 38(6):1139-1145

7. Wiaux J-P, Waefler J-P (1995) Recycling zinc batteries: an economical challenge in consumer waste management. J Power Sources 57(1-2):61-65

8. Xie Z, Liu Q, Chang Z, Zhang X (2013) The developments and challenges of cerium half-cell in zinc-cerium redox flow battery for energy storage. Electrochim Acta 90:695-704

9. Jolly JH (1992) "Zinc," Mineral Commodity Summaries 1992. U.S. Department of the Interior Bureau of Mines, Washington, DC

10. Jolly JH (1990) "Zinc," Minerals Yearbook 1989. U.S. Department of the Interior Bureau of Mines, Washington, DC

11. Williams RL (1990) The Monaca Electrothermic Smelter - The Old Becomes the New," Lead-Zinc '90. In: Mackey TS, Prengaman RD, (eds.), The Minerals, Metals \& Materials Society, Philadelphia. 
12. Environmental Assessment of the Domestic Primary Copper (1978) Lead and Zinc Industries, EPA-600/2-82-066. U.S. Environmental Protection Agency, Cincinnati, $\mathrm{OH}$

13. Patra SN, Lin RJT, Bhattacharyya D (2010) Regression analysis of manufacturing electrospun nonwoven nanotextiles. J Mater Sci 45(14):3938-3946

14. de Faoite D, Browne DJ, Stanton KT (2013) Regression analysis of temperature-dependent mechanical and thermal properties of dielectric technical ceramics. J Mater Sci 48(1):451-461

15. Manière $C$, Durand $L$, Chevallier $G$, Estournès $C$ (2018) A spark plasma sintering densification modeling approach: from polymer, metals to ceramics. J Mater Sci 53(10):7869-7876

16. Wang X, Lu J, Che Ch, Kong G (2008) The behavior of lead during the solidification of $\mathrm{Zn}-0.1 \mathrm{Al}-0.1 \mathrm{~Pb}$ coating on batch hotdipped steel. Appl Surf Sci 254:2466-2471

17. Valdez S, Pérez R, Rodriguez-Diaz RA, Angeles-Chávez C, Casolco SR (2010) Relationship between silver concentration with microstructural and mechanical properties of rolled AIZn alloy. Mater Sci Eng, A 527:3085-3090

18. Lehuy H, Masounave J, Blain J (1985) Rheological behaviour and microstructure of stir-casting zinc-aluminium alloys. J Mater Sci 20(1):105-113

19. Mykura N, Murphy S (1986) Metallography and properties of the cast ZA alloys. In: Lewis GP, Barnhurst RJ, Loong CA (eds) Proc. Int. Symp. on Zinc-Aluminium (ZA) Casting Alloys, Canadian Institute of Metals (CIM), Toronto, Ontario, August, 1986, pp 45-55

20. Dahotre NB, McCay TD, McCay MH (1990) Laser surface modification of zinc-base composites. JOM 42(6):44-47

21. Gao X, Nie JF (2007) Characterization of strengthening precipitate phases in a Mg-Zn alloy. Scripta Mater 56(8):645-648

22. Choi HJ, Shin JH, Min BH, Bae D (2010) Deformation behavior of $\mathrm{Al}-\mathrm{Si}$ alloy based nanocomposites reinforced with carbon nanotubes. Compos A Appl Sci Manuf 41(2):327-329

23. Liu HT, Sun LZ (2005) Multi-scale modeling of elastoplastic deformation and strengthening mechanisms in aluminum-based amorphous nanocomposites. Acta Mater 53(9):2693-2701

24. Paramsothy $M$, Gupta $M$ (2013) In-situ rod-shaped nanoparticles in Mg-Zn magnesium alloy: towards high strength and ductility. J Alloy Compd 580:604-610

25. Kounis A, Miehe G, Fuess H (2000) Investigation of icosahedral phases in the $\mathrm{Zn}-\mathrm{Mg}-(\mathrm{Y}, \mathrm{Er})$ system by high resolution transmission electron microscopy. Mater Sci Eng A 294-296:323-326

26. Bae D, Lee MH, Kim KT, Kim WT, Kim DH (2002) Application of quasicrystalline particles as a strengthening phase in $\mathrm{Mg}-\mathrm{Zn}-\mathrm{Y}$ alloys. J Alloy Compd 342(1-2):445-450

27. Bae D, Kim SH, Kim DH, Kim WT (2002) Deformation behavior of $\mathrm{Mg}-\mathrm{Zn}-\mathrm{Y}$ alloys reinforced by icosahedral quasicrystalline particles. Acta Mater 50(9):2343-2356

28. Charaniya S, Le H, Rangwala H, Mills K, Johnson K, Karypis G, Hu WS (2010) Mining manufacturing data for discovery of high productivity process characteristics. J Biotechnol 147(3-4):186-197

29. Pan WT (2010) Combining fuzzy sammon mapping and fuzzy clustering approach to perform clustering effect analysis: take the banking service satisfaction as an example. Expert Syst Appl 37(6):4139-4145
30. Katipamula S, Reddy T, Claridge DE (1998) Multivariate regression modeling. J Sol Energy Eng 120:177

31. Hygh JS, DeCarolis JF, Hill DB, Ranji RS (2012) Multivariate regression as an energy assessment tool in early building design. Build Environ 57:165-175

32. Strydom JJ, Miskin JJ, McCoy JT, Auret L, Dorfling C (2018) Fault diagnosis and economic performance evaluation for a simulated base metal leaching operation. Miner Eng. https://doi. org/10.1016/J.MINENG.2018.03.029

33. Dorfling C, Akdogan G, Bradshaw SM, Eksteen JJ (2013) Modelling of an autoclave used for high pressure sulphuric acid/oxygen leaching of first stage leach residue. Part 1: model development. Miner Eng 53:220-227. https://doi.org/10.1016/J.MINENG. 2013.03.005

34. Dorfling C, Akdogan G, Bradshaw SM, Eksteen JJ (2013) Modelling of an autoclave used for high pressure sulphuric acid/oxygen leaching of first stage leach residue, Part 2: model application. Miner Eng 53:213-219. https://doi.org/10.1016/J.MINENG. 2013.03.011

35. Miskin JJ, Lindner BS, Auret L, Dorfling C, Bradshaw SM (2016) Fault detection for simulated valve faults in a high pressure leaching process. IFAC-PapersOnLine 49:394-399. https://doi. org/10.1016/j.ifacol.2016.07.372

36. Saldaña M, Toro N, Castillo J, Hernández P, Navarra A (2019) Optimization of the heap leaching process through changes in modes of operation and discrete event simulation. Minerals 9(7):421. https://doi.org/10.3390/min9070421

37. Li J, Zhang Y, Du D, Liu Z (2017) Improvements in the decision making for Cleaner Production by data mining: case study of vanadium extraction industry using weak acid leaching process. J Clean Prod 143:582-597. https://doi.org/10.1016/j.jclep ro.2016.12.071

38. Kantardzic M (2011) Data mining: concepts, models, methods, and algorithms. John Wiley \& Sons, New York

39. Han J, Pei J, Kamber M (2011) Data mining: concepts and techniques. Elsevier, Amsterdam

40. Tan PN, Steinbach M, Kumar V (2013) Data mining cluster analysis: basic concepts and algorithms. Introduction to data mining, 487-533.

41. Cios KJ, Pedrycz W, Swiniarski RW, Kurgan LA (2007) Data mining: a knowledge discovery approach. Springer Science \& Business Media, Berlin

42. Montgomery DC, Runger GC (2010) Applied statistics and probability for engineers. John Wiley \& Sons, New York

43. Cook RD (1977) Detection of influential observation in linear regression. Technometrics 19(1):15-18

44. Cook RD (1979) Influential observations in linear regression. J Am Stat Assoc 74(365):169-174

45. Efroymson, M. A. (1960). Multiple regression analysis. Mathematical methods for digital computers, 191-203.

46. Montgomery DC, Peck EA, Vining GG (2012) Introduction to linear regression analysis, vol 821. John Wiley \& Sons, New York

Publisher's Note Springer Nature remains neutral with regard to jurisdictional claims in published maps and institutional affiliations. 